\title{
10
}

\section{Observations on the Northern Moluccan excavated animal bone and shell collections}

\author{
Jennifer R. Hull, Philip Piper, Geoffrey Irwin, Katherine Szabó, \\ Annette Oertle, and Peter Bellwood
}

Due to their isolation, the Northern Moluccan islands today contain only a very impoverished and mainly marsupial indigenous Wallacean vertebrate fauna that includes the cuscuses Phalanger ornatus and Phalanger alexandriae (Flannery and Boeadi 1995), the sugar glider Petaurus breviceps (not found so far in any archaeological contexts in the Northern Moluccas), and the large placental rodent Rattus morotaiensis (Flannery 1995a). These species have been supplemented by several humanly mediated introductions of placental mammal species, such as Rattus exulans, R. tanezumi, Suncus marinus, Paradoxurus hermaphroditus, Cervis timorensis, plus pigs and dogs (Flannery et al. 1995).

The 1990s excavations in the Moluccas produced several substantial vertebrate assemblages dating to the late Pleistocene and Holocene. The initial report on the assemblage from Gua Siti Nafisah on Halmahera was published in 1995 (Flannery et al. 1995), in which an extinct wallaby (Dorcopsis sp.) and a bandicoot related to the Echymipera/Rhynchomeles group found in the Holocene deposits of that cave were described as 'quite unexpected', and reported as occurring with the extant Moluccan cuscus species Phalanger ornatus. The opinion was expressed that the two extinct marsupial species were probably 'indigenous elements in the fauna'. The succeeding report (Flannery et al. 1998) announced the further discovery of wallaby bones in Golo Cave and Wetef rockshelter on Gebe, and of Rattus morotaiensis on Morotai.

This second report established that the wallaby was not found on Kayoa or Morotai (hence, so far only on Halmahera and Gebe), and that the bandicoot was only found in Gua Siti Nafisah on Halmahera. Further, the main author, Tim Flannery, suggested on the basis of his dental comparisons that the Halmahera and Gebe wallaby species was sufficiently close in its dentition to an extant indigenous wallaby species (Dorcopsis muelleri mysoliae) on Misool Island, southwest of the Bird's Head of Papua, to represent a deliberate human translocation, possibly from there. The absence of this taxon from the modern Northern Moluccan fauna and its apparently abrupt Early Holocene appearance in the archaeological record of Gebe Island thus raised important questions about the origin of this species, the potential timing of its introduction to Gebe, and the reasons for its eventual extinction. 
The proposed deliberate introduction of $D$. muelleri on to Halmahera and Gebe Islands has played a pivotal role in arguments supporting human mediated animal translocation in the Late Pleistocene and Early Holocene in Wallacea and Melanesia, and the implications for behavioural complexity as expressed through seafaring (Bellwood et al. 1998; Matisoo-Smith 2007). No similar suggestions of translocation were made for the bandicoot, since the sample size was so small.

\section{Part 1: Animal bones: All sites except Wetef (Jennifer R. Hull, Philip Piper, and Peter Bellwood)}

\section{Methods}

This study deals with all the animal bones from seven sites: Tanjung Pinang with Daeo Caves 1 and 2 (Morotai Island), Uattamdi (Kayoa Island), Um Kapat Papo and Golo (Gebe Island), and Siti Nafisah (Halmahera Island). These sites provided the raw data for the Master's thesis completed at The Australian National University (ANU) by Jennifer R. Hull in 2014, under the supervision of Philip Piper and Peter Bellwood (Hull 2014). The Wetef fauna is described later in this chapter by Geoffrey Irwin. The emphases in this section are on taphonomy, tooth wear and eruption sequences, age profiling, degrees of fragmentation, and taxonomic identification of species. Altogether, a total of 16,984 fragments of bone were recovered from these seven sites, which are described individually in Chapters 2 to 5 . The identifications and counts by Jennifer R. Hull for Golo Cave on Gebe are given in Tables 10.1 to 10.3.

A taphonomic analysis of the bone from each site was undertaken to identify the pre- and postdepositional processes that might have influenced preservation, following Behrensmeyer (1978) and Lyman (1994). Weathering stages were adapted from Behrensmeyer (1978) and recorded for all fragments. High-resolution images of important taphonomic indicators, significant teeth, and other selected elements were obtained with a Canon EOS 60D camera with extension tubes and a Canon EOS 700D with a $100 \mathrm{~mm}$ macro lens. A light microscope was used for a more detailed analysis of tooth wear and eruption sequences. Unless modern breakage was detected, maximum length was recorded for each fragment to identify fragmentation patterns. Diagnostic elements of bone were identified to the highest taxonomic level possible, using the mammal skeletal reference collections housed in the School of Archaeology and Anthropology in the ANU and the Australian Museum in Sydney, and also the fish bone comparative collection in the School of Archaeology and Natural History in the ANU.

For Dorcopsis, measurements of all the complete archaeological teeth were taken in terms of buccal-lingual breadth of the mesial and distal columns, and molar crown length measured from cingulum to cingulum (Pasveer 2004). These dental measurements were compared with those of dentitions of known species of Dorcopsis held in the storage facility at the Australian Museum in Sydney. The data were used in a series of multivariate discriminant function analyses that compared M1 and M2, M1 and M3, and M2 and M3. The aim was to determine whether the now-extirpated Gebe Island wallaby bore any metrical relationship with known extant species of wallaby. These statistical analyses were applied following Groves and Flannery (1989). For the age profiling of the assemblage, tooth eruption sequences were analysed using standards based on the detailed descriptions of eruption stages presented by van Deusen (1957). This scheme took into consideration both tooth development and eruption.

Pasveer (2004) identified seven tooth wear stages within an assemblage of Dorcopsis muelleri recovered from the Ayamaru region of the Bird's Head Peninsula that permitted the wear of each individual tooth to be analysed and recorded. Stage 1 shows wear but no exposed dentine, and 
stage 7 is where the entire surface of the tooth is a dentine 'pool'. For this study, we also included a wear stage 0 , whereby the tooth exhibits no wear. Also, it was noted during the study that the molars tend to wear on the buccal lophs before the lingual, and as such the wear stages have been adapted to this description. These data enabled the determination of adult age structure as well as the developmental stages from tooth eruption data (see also Pasveer 2004) of the Dorcopsis community recovered from the various cave sites in the Northern Moluccas.

\section{Taphonomic observations}

\section{Golo Cave, Gebe Island}

The Golo Cave excavations produced a total of 6364 fragments of animal bone, divided between two trenches (LMN4-7, number of identified specimens (NISP): 5467; and H4-H5, NISP: 887) created from a grid of $1 \mathrm{~m}$ squares. Golo Squares LMN4-7 were excavated to bedrock at $240 \mathrm{~cm}$. The vertebrate remains were concentrated here between $15-20 \mathrm{~cm}$ and $80-85 \mathrm{~cm}$, and only continued to a maximum depth of $135 \mathrm{~cm}$, despite cultural materials continuing to bedrock at $240 \mathrm{~cm}$ (Table 2.2, second column from left). Golo Squares $\mathrm{H} 4$ and $\mathrm{H} 5$ were only excavated to $90 \mathrm{~cm}$ and $140 \mathrm{~cm}$ respectively owing to the high level of the bedrock in this location, and faunal remains were not present in either below $90 \mathrm{~cm}$. Golo Cave thus has no surviving animal bone from its lower layers below $135 \mathrm{~cm}$, for reasons that currently remain unknown.

In Square M6 there was some evidence of mixing in the sequence, with a small concentration of modern yellow bone of unidentified mammal origin present at $30-40 \mathrm{~cm}$, also in M4 at $55-60 \mathrm{~cm}$. There were also fragments of mammal long bone, an acetabulum $(\mathrm{M} 7,70-75 \mathrm{~cm})$ and two ribs (M5, 40-45 cm), with apparent iron oxide staining. Trench H4-H5, however, was mixed throughout with modern yellow fragments of bone from a variety of taxa.

Generally, modifications associated with subaerial weathering of bone in LMN4-7 were present, but fairly minimal at stages 1 or 2 (Behrensmeyer 1978), perhaps indicating relatively short exposure prior to burial. However, below $40 \mathrm{~cm}$ depth the proportion of bones demonstrating weathering at stage 3 and above increased. An overwhelming majority of bones in $\mathrm{H} 4-\mathrm{H} 5$ were highly weathered, at stage 3 or higher. This indicates that many bones in this trench probably spent a considerable duration of time in the subaerial zone prior to their eventual burial. Many bones also had concretions resulting from precipitation of calcium carbonate dissolved in percolating ground water (Fig. 10.1).

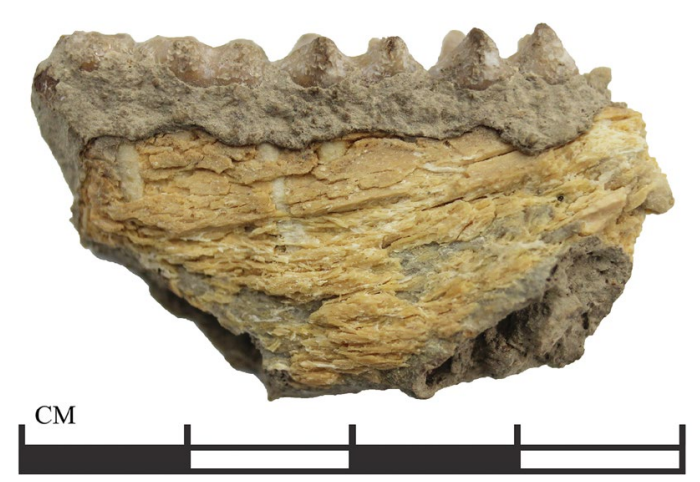

Figure 10.1 Dorcopsis mandible from Golo $\mathrm{H} 5$, 40-45 cm, with stage 5 weathering and calcium carbonate concretion.

Source: Jennifer R. Hull.

Burnt bone occurred throughout LMN4-7, with the highest frequency below $30 \mathrm{~cm}$. Fully calcined bone occurred mostly between 30 and $70 \mathrm{~cm}$. Much of the H4-5 assemblage was highly burnt, occasionally to a blue or white colour, but no concentrations of burnt bone were found. There was also evidence of butchery on several Dorcopsis, phalanger, lizard and pig bones, and on other unidentified mammal fragments. These cut marks occurred predominantly on limb bones and pelvic fragments. 


\section{Um Kapat Papo (UKP), Gebe Island}

UKP yielded 566 fragments of animal bone that continued down to the fairly shallow bedrock at a maximum of $85 \mathrm{~cm}$. This site had much less reworking in terms of bone weathering stages than Golo, with light-coloured modern bones concentrated towards the surface and darker brown bones apparently contemporary with their stratigraphic depths below. Also consistent with a more stable environment is the observation that the entire UKP assemblage is at weathering stage 3 or lower, with the majority of bones at stage 1 . There was also a much lower concentration of burnt bone compared to Golo, and no calcium carbonate concretions on the bones. There are also signs of butchery at UKP-for example, a cut mark found on the antero-lateral margin close to the distal articular end of a phalanger humerus. This likely represents an attempt to separate the humerus from the radius and ulna during carcass dismemberment.

\section{Tanjung Pinang, Morotai Island}

Only 213 fragments of animal bone were recovered from Tanjung Pinang rockshelter, and whilst the trench was excavated to a depth of $240 \mathrm{~cm}$, no animal bone or evidence of human occupation was recovered from Layer 2, below $80-85 \mathrm{~cm}$ (Chapter 3). The admixture of pieces of bone varying in colour from light yellowish-brown to dark brown in the upper $25-30 \mathrm{~cm}$ suggests considerable reworking of deposits. Low weathering stages (mostly stage 1) were recorded throughout the sequence, except in the upper few centimetres where higher stages were recorded, but there were no calcium carbonate concretions. No butchery or other forms of human modification to bones were identified in the assemblage, despite relatively high abundances of phalanger and fish bones.

\section{Daeo Caves 1 and 2, Morotai Island}

Daeo Cave 1 produced just 16 fragments of light yellowish-brown bone concentrated in the upper horizons. The majority demonstrated some significant weathering at stage 3 , suggesting subaerial exposure. No butchery or other humanly mediated modifications were recorded, nor were there any calcium carbonate concretions.

Daeo Cave 2 produced 2145 bone fragments, varying in colour from light brown higher up to dark brown at greater depth. Some reworking and vertical movement was evident, with light coloured and apparently young yellowish-brown fragments of bone recorded to depths of $80-85 \mathrm{~cm}$. The majority of bones were weathered at stage 1 , suggesting only limited exposure to subaerial weathering. Three fragments of phalanger and one fragment of unidentifiable fish bone were heavily concreted with calcium carbonate. Lightly burnt fragments of bone were restricted to $15-20 \mathrm{~cm}$ and $75-80 \mathrm{~cm}$.

\section{Gua Siti Nafisah, Halmahera Island}

Gua Siti Nafisah produced a total of 6727 bone fragments distributed between Squares F5-F8 (6441), E12 (45), and J10 (241). Deposit reworking is revealed by the modern yellow and older brown fragments found together throughout the sequence, with no apparent concentrations. Square F6 contained the highest numbers of reworked bones. There was consistent evidence of low sub-aerial weathering, with all levels containing high levels of stage 1 . There were also relatively few fragments with calcium carbonate concretion, although they did appear in small pockets in spits C3, D2-D3, and E2. Cut marks occurred on the long bones of phalanger, predominantly from the 'sink area' along the southern wall of the cave entrance (Fig. 10.2) and in spit A8 of Square F6. They occurred also on bones of Dorcopsis (in F6 spit A4 and F8 spit D1), pig (from J10 extension, Layer C2), and reptiles. 


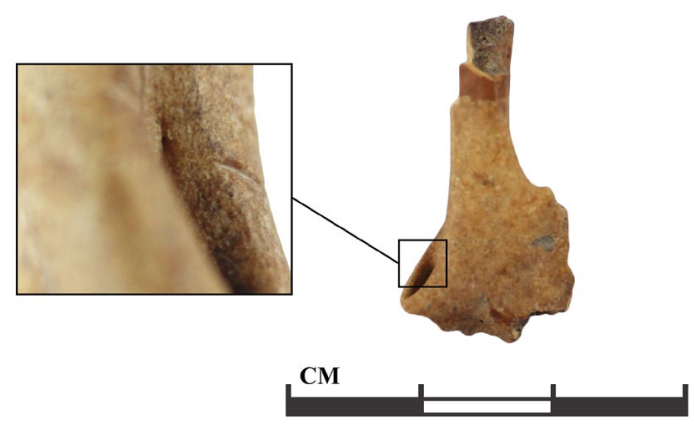

Figure 10.2 Phalanger humerus fragment from Gua Siti Nafisah (F6, sink area against cave wall) with cut mark on the medial margin of the distal end.

Source: Jennifer R. Hull.

\section{Uattamdi, Kayoa Island}

The 1244 bone fragments recovered from Uattamdi show consistent mixing between layers, and have the highest average fragment dimension, at $58.79 \mathrm{~mm}$. The overwhelming majority of the fragments have stage 1 weathering, indicating rapid burial with no post-depositional taphonomic processes affecting integrity. There are no calcium carbonate concretions or evidence of butchery. The stratigraphy reveals ash layers at the top of Layer A, middle and bottom of Layer C, and the middle of Layer $\mathrm{D}$, consistent with the distribution of burnt faunal remains.

\section{Taxonomic identifications}

\section{Golo Cave, Gebe Island}

In Golo Squares LMN4-7, 868 out of the total of 5467 fragments could be identified to family or higher taxonomic level (Tables 10.110.3). These include Osteichthyes and Elasmobranchii (NISP: 85), Reptilia (NISP: 74), Dorcopsis (minimum number of individuals (MNI): 21; NISP: 358), phalanger (MNI: 20; NISP: 229), Chiroptera (NISP: 96), Muridae (NISP: 16), Sus cf. scrofa (NISP: 7) and Canis familiaris (NISP: 2).

The Dorcopsis remains are dominated by fragments of upper limbs, crania, and pelves, and smaller numbers of elements such as scapulae, lower limb bones, tarsals, and vertebrae that may suggest entire carcasses were being transported to the site. The pig remains occur at $5-10$ and $10-15 \mathrm{~cm}$, in possible association with the supine and ochre-covered human burial directly dated to 2314-1415 cal. BP (Table 1.1, ANU 11818). There are also three possible pig fragments at $65-70 \mathrm{~cm}$, but these are likely a result of disturbance. The only two dog bones from Golo were found at 50-55 and $85-90 \mathrm{~cm}$, although the deeper fragment may be a modern intrusion. The Dorcopsis bones in this trench extended from $10-15$ to $90-95 \mathrm{~cm}$, with a single fragment at $100-115 \mathrm{~cm}$. The uppermost fragments may have associated dates with the human burial mentioned above, and the closest associated date for the lowest fragments is from a Nerita marine shell dated to 12,04411,376 cal. BP (M5 135-140 cm, Table 1.1, ANU 9769). Of the fish, two families and one sub-class were identifiable: Serranidae, Scaridae, and Elasmobranchii, respectively.

In Golo Squares H4-H5, 887 bone fragments were recovered. Fish remains were quite common throughout the sequence, with the highest numbers per spit $(>100)$ between $30-35$ and $50-55 \mathrm{~cm}$. Below $50-55 \mathrm{~cm}$, fish bones diminished in number until disappearance at $80-90 \mathrm{~cm}$. Dorcopsis bones (MNI: 24; NISP: 150) were recorded from $25-30 \mathrm{~cm}$ to $75-80 \mathrm{~cm}$, with a peak at 30-35 cm. Sixty-two fragments of Dorcopsis dentition were recovered: 45 mandibular and 17 maxillary. The Dorcopsis remains in this trench are also dominated by cranial and lower limb fragments. The presence of various other skeletal elements may suggest that entire carcasses were being transported to the site. The youngest phalanger bones (MNI: 6; NISP: 23) were recorded at $30-35 \mathrm{~cm}$, with the highest frequency at $40-45 \mathrm{~cm}$. A phalanger ulna and a Dorcopsis maxilla were both recorded at $80-90 \mathrm{~cm}$, these being the lowest bones recovered from the sequence.

In order to verify the ages of some of the deepest and potentially oldest fragments of Dorcopsis at Golo, eight dental fragments were sent to the ANU AMS Radiocarbon Laboratory for C14 testing. Unfortunately, nitrogen testing of the bone indicated that insufficient collagen 
remained to provide an accurate date. However, two specimens were successfully dated using tooth enamel, a right maxillary fragment containing a fully erupted sequence of M2-M4 from $75-80 \mathrm{~cm}$, and a left maxillary fragment containing a fully erupted $\mathrm{P} 4$ from $80-90 \mathrm{~cm}$. These produced dates of 7675-7515 (S-ANU 36407) and 7982-7738 cal. BP (S-ANU 36409) respectively (Table 1.1 ).

It is recognised that tooth enamel dates are often younger than expected, due to the presences of unremoved contaminants (Zazzo 2014; Zazzo and Saliège 2011). In his recent synthesis of dates on unburnt apatite, Zazzo (2014) found that during the Holocene they are normally a few hundred C14 years too young, and beyond $8000 \mathrm{BP}$ this error increases substantially (Zazzo 2014:Table 4, Figure 11). Therefore, the enamel dates for Golo Dorcopsis teeth should be considered minimum ages only. Nevertheless, the dating achieved the objective of demonstrating that Dorcopsis was present on Gebe Island from the Early Holocene onwards. Attention can also be also drawn to the two direct $\mathrm{C} 14$ dates on wallaby bone from Wetef rockshelter, discussed below by Geoffrey Irwin in this chapter. These are 6487-6182 (NZA 8387) and a surprisingly young 906-570 cal. BP (NZA 8369).

Table 10.1 Reptile and fish remains from Golo LMN4-7, recorded by number of individual specimens (NISP) and depth (cm).

\begin{tabular}{|c|c|c|c|c|c|c|c|}
\hline \multirow[t]{2}{*}{ Depth } & \multicolumn{2}{|c|}{ Reptile } & \multicolumn{4}{|c|}{ Fish } & \multirow[t]{2}{*}{ Unid. all bone } \\
\hline & Monitor Lizard & Snake & Scaridae & Serranidae & Elasmobranchi & Unid. fish bones & \\
\hline $0-5$ & & & & & & & 1 \\
\hline \multicolumn{8}{|l|}{$5-10$} \\
\hline $10-15$ & & & & & & 1 & 2 \\
\hline $15-20$ & & 2 & & & & 6 & 27 \\
\hline $20-25$ & 1 & 2 & & & & 1 & 62 \\
\hline $25-30$ & 5 & 3 & & & & 1 & 168 \\
\hline $30-35$ & 13 & 4 & & 1 & & 9 & 256 \\
\hline $35-40$ & 3 & 6 & 1 & & & 11 & 39 \\
\hline $40-45$ & 3 & 14 & & 1 & 1 & 17 & 25 \\
\hline $45-50$ & 2 & 1 & & & 1 & 3 & 21 \\
\hline $50-55$ & 6 & 1 & & & 1 & 7 & 63 \\
\hline $55-60$ & & 2 & & & & 6 & 29 \\
\hline $60-65$ & 1 & 4 & & & & 3 & 59 \\
\hline $65-70$ & & & & & & & 4 \\
\hline $70-75$ & & & & & & & 13 \\
\hline $75-80$ & & & & & & 1 & 9 \\
\hline $80-85$ & 1 & & & & & & \\
\hline $85-90$ & & & & & & 4 & \\
\hline $90-95$ & & & & & & 3 & \\
\hline $95-100$ & & & 2 & & & & 1 \\
\hline \multicolumn{8}{|l|}{ 100-105 } \\
\hline $105-110$ & & & & & & & 1 \\
\hline $110-115$ & & & & 1 & & 1 & 1 \\
\hline $115-120$ & & & & & & 1 & \\
\hline \multicolumn{8}{|l|}{$120-125$} \\
\hline \multicolumn{8}{|l|}{$125-130$} \\
\hline $130-135$ & & & & & & 1 & \\
\hline Totals & 35 & 39 & 3 & 3 & 3 & 76 & 781 \\
\hline
\end{tabular}

The right-hand column shows unidentified (unid.) remains of all species too fragmentary for any higher identification. Source: Jennifer R. Hull. 
Table 10.2 Mammal bones from Golo LMN4-7, recorded by number of individual specimens (NISP) and depth $(\mathrm{cm})$.

\begin{tabular}{|c|c|c|c|c|c|c|c|c|}
\hline Depth & Dorcopsis & Phalanger & Dog & Pig & Muridae & Peramelidae & Megachiroptera & Unid. mammal bone \\
\hline$?$ & 24 & 2 & & & & & & 20 \\
\hline $0-5$ & & & & & & & & 5 \\
\hline $5-10$ & & 1 & & 1 & & & & 11 \\
\hline $10-15$ & 4 & 2 & & 3 & & & & 27 \\
\hline $15-20$ & 17 & 13 & & & & & & 90 \\
\hline $20-25$ & 16 & 23 & & & & & 11 & 84 \\
\hline $25-30$ & 33 & 27 & & & 1 & & 4 & 262 \\
\hline $30-35$ & 38 & 34 & & & 2 & & 37 & 525 \\
\hline $35-40$ & 68 & 49 & & & 3 & & 1 & 786 \\
\hline $40-45$ & 63 & 33 & & & 2 & & 17 & 773 \\
\hline $45-50$ & 10 & 6 & & & 5 & & 1 & 295 \\
\hline $50-55$ & 22 & 19 & 1 & & & & 3 & 325 \\
\hline $55-60$ & 20 & 8 & & & & & 6 & 200 \\
\hline $60-65$ & 10 & 5 & & & & & 5 & 183 \\
\hline $65-70$ & 12 & 4 & & 3 & & 1 & 1 & 74 \\
\hline $70-75$ & 7 & 1 & & & 1 & & & 38 \\
\hline $75-80$ & & & & & & & 1 & 24 \\
\hline $80-85$ & 6 & & & & & & & 24 \\
\hline $85-90$ & 2 & & 1 & & & & 3 & 28 \\
\hline $90-95$ & 2 & 2 & & & & & 3 & 17 \\
\hline $95-100$ & & & & & & & & 8 \\
\hline 100-105 & & & & & 1 & & 1 & 4 \\
\hline 105-110 & & & & & & & & 3 \\
\hline 110-115 & 1 & & & & & & & 7 \\
\hline $115-120$ & & & & & 1 & & & \\
\hline 120-125 & & & & & & & & 1 \\
\hline 125-130 & & & & & & & & 1 \\
\hline 130-135 & & & & & & & 2 & 3 \\
\hline Total & 358 & 229 & 2 & 7 & 16 & 1 & 96 & 3818 \\
\hline
\end{tabular}

The counts presented here differ slightly from those in Flannery et al. (1998:Table 2) for reasons that are not entirely clear, but that may relate to differing analyst decisions about ambiguous fragments, plus the possibility that some specimens have been removed since the original bags were brought to Australia. The 1998 counts were also for post-cranial bones only.

Source: Jennifer R. Hull.

Table 10.3 Animal bones from Golo H4-H5, recorded by number of individual specimens (NISP) and depth $(\mathrm{cm})$.

\begin{tabular}{|c|c|c|c|c|c|c|c|c|c|c|}
\hline \multirow[t]{2}{*}{ Depth } & \multicolumn{2}{|c|}{ Reptile } & \multicolumn{2}{|c|}{ Fish } & \multicolumn{5}{|c|}{ Mammal } & \multirow{2}{*}{$\begin{array}{l}\text { Unid. } \\
\text { all bone }\end{array}$} \\
\hline & $\begin{array}{c}\text { Monitor } \\
\text { lizard }\end{array}$ & Snake & Scaridae & $\begin{array}{l}\text { Unid. } \\
\text { fish }\end{array}$ & Pteropodidae & Dorcopsis & Phalanger & Muridae & $\begin{array}{c}\text { Unidentified } \\
\text { mammal }\end{array}$ & \\
\hline $0-5$ & & & & & & 1 & & & & \\
\hline $5-10$ & & & & 2 & & & & & & 5 \\
\hline $10-15$ & & & & 1 & & & & & & 1 \\
\hline $15-20$ & & & & 7 & 1 & & & & 1 & 6 \\
\hline $20-25$ & & 1 & & 6 & & & & & & 6 \\
\hline $25-30$ & & & & 1 & & 3 & & & 1 & 12 \\
\hline 30-35 & 1 & & & & & 40 & 5 & & 41 & 52 \\
\hline $35-40$ & & & & 13 & 2 & 33 & 9 & 2 & 22 & 84 \\
\hline $40-45$ & & & & 5 & & 33 & 2 & 1 & 24 & 93 \\
\hline
\end{tabular}




\begin{tabular}{|c|c|c|c|c|c|c|c|c|c|c|}
\hline \multirow[t]{2}{*}{ Depth } & \multicolumn{2}{|c|}{ Reptile } & \multicolumn{2}{|c|}{ Fish } & \multicolumn{5}{|c|}{ Mammal } & \multirow{2}{*}{$\begin{array}{l}\text { Unid. } \\
\text { all bone }\end{array}$} \\
\hline & $\begin{array}{l}\text { Monitor } \\
\text { lizard }\end{array}$ & Snake & Scaridae & $\begin{array}{l}\text { Unid. } \\
\text { fish }\end{array}$ & Pteropodidae & Dorcopsis & Phalanger & Muridae & $\begin{array}{c}\text { Unidentified } \\
\text { mammal }\end{array}$ & \\
\hline $45-50$ & & & 1 & 2 & & 12 & 1 & & 52 & 60 \\
\hline $50-55$ & 1 & 1 & & 3 & & 13 & 5 & 1 & 33 & 69 \\
\hline $55-60$ & & & & 1 & & 6 & 1 & & 15 & 5 \\
\hline $60-65$ & & & & 1 & & 3 & & & 20 & 7 \\
\hline $65-70$ & & & & & & 1 & & & 2 & 7 \\
\hline $70-75$ & & & & & & 1 & & 2 & 3 & 2 \\
\hline $75-80$ & & & & 1 & & 3 & & & 15 & 5 \\
\hline $80-85$ & & & & & & & & & & \\
\hline $85-90$ & & & & 1 & & 1 & 1 & & 12 & \\
\hline $90-95$ & & & & & & & & & & \\
\hline $95-100$ & & & & & & & & & & \\
\hline Total & 2 & 2 & 1 & 44 & 3 & 150 & 24 & 6 & 241 & 414 \\
\hline
\end{tabular}

The right-hand column shows unidentified (unid.) remains of all species too fragmentary for any higher identification. Source: Jennifer R. Hull.
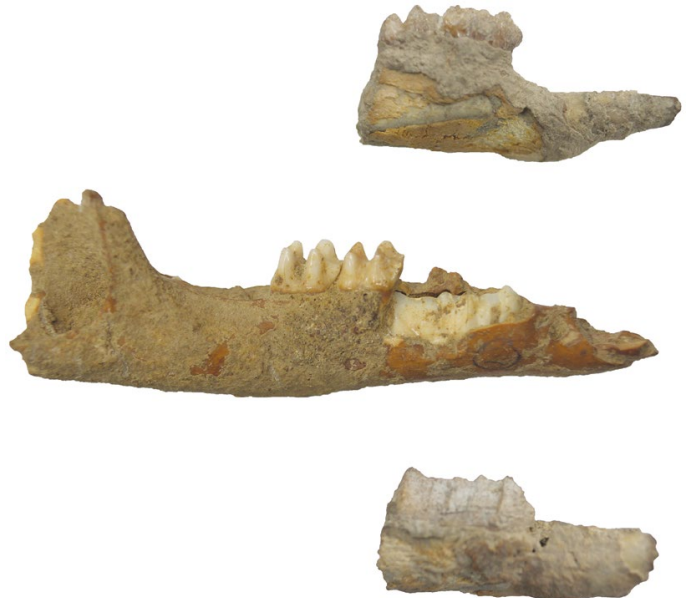

CM

Figure 10.3 Three Dorcopsis mandibles from Golo displaying different stages of tooth eruption.

Dp3 and Dp4 are fully erupted (top), M4 is beginning to erupt whilst the P4 is still in the crypt after having expelled the Dp3 and Dp4 (centre), and the fully erupted P4 (bottom).

Source: Jennifer R. Hull.

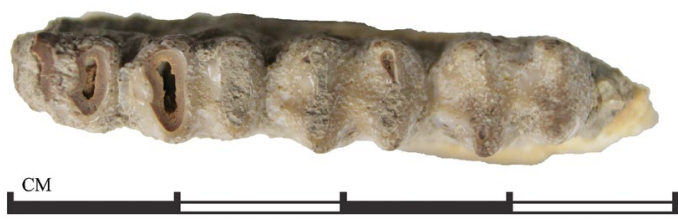

Figure 10.4 A left Dorcopsis mandible from Golo $\mathrm{H} 5,40-45 \mathrm{~cm}$, displaying tooth wear stages on four molars (M1-6, M2-6, M3-3 and M4-2).

Source: Jennifer R. Hull.
Out of the total number of Dorcopsis cranial fragments, seven were determined to be of juvenile age, distinguished by an absence of $\mathrm{P} 4$ and the presences of Dp3 and/or Dp4. The eruption stages also indicate that the majority of individuals were adults, with all molars fully erupted $(n=22)$. Of the seven juveniles, only five had a fully erupted M1, and three a fully erupted M2. Of the adult specimens, 11 showed evidence that the M4 was still below the jaw bone (stage 0 ), and seven of these exhibited a partially erupted (stage 2-3) M3. Thus, both tooth eruption patterns and tooth wear on the Dorcopsis molars indicate that the captured population consisted predominantly of juvenile individuals and older adults, with only a few mature adults with fully erupted M4s (Figs 10.3 and 10.4). 


\section{Um Kapat Papo, Gebe Island}

The most common mammals recorded at Um Kapat Papo were Dorcopsis (MNI: 10; NISP: 44), phalanger (MNI: 4; NISP: 31), Osteichthyes (NISP: 30), and Muridae (MNI: 3; NISP: 40). The dog was represented by a single vertebra in Layer 3, spit 20-25 cm, and another in Layer 3, spit 25-30 cm. With the exception of a fragment of Dorcopsis recorded in Layer 2, macropod remains (both Dorcopsis and phalanger) were only recorded from Layer 3, loosely associated with a marine shell date of $7330-7028 \mathrm{cal}$. BP at 55-65 cm in Layer 3 (Table 1.1, ANU 9318). Only one fragment of Osteichthyes was identifiable to family, Scaridae, at Layer 3, spit 30-40 cm.

\section{Analysis of the Gebe Island Dorcopsis dentition}

Pasveer (2004) argued that there was strong sexual dimorphism evident in the 3rd and 4th molars between modern male (large) and female (small) D. muelleri. If sexual dimorphism could be ascertained in the Gebe sample, then it would have been possible to differentiate males and females and interpret the Dorcopsis hunted population structure. However, Pasveer's original study was based on one single sample each of male and female $D$. muelleri that were then available for study in the Australian Museum collection. In our study, the archaeological assemblage was compared to a much larger sample (45 individuals of four species) of male and female Dorcopsis dentitions in the Australian Museum. From this larger sample there is no evidence of sexual dimorphism in the dentition, but as noted below by Geoffrey Irwin for the Wetef Dorsopsis sample, and earlier by Tim Flannery and colleagues (1998), there is substantial variation in the size of fragmentary post-cranial elements that suggest sexual dimorphism in overall body size.

The sample of Dorcopsis cranial elements from Um Kapat Papo is quite small, but it shows similar results to Golo Cave in that the majority of individuals were adults with erupting or fully erupted M4s, with four potentially more mature in age with all teeth fully erupted and stage 4 or higher tooth wear stages. There are no examples with deciduous teeth, but there are two sub-adult mandibles, one with an erupting P4 and another with a P4 in the crypt.

Following Groves and Flannery (1989), a discriminant function analysis was undertaken to compare the archaeological dentitions of Dorcopsis with specimens of known species and origin held in the Australian Museum. This analysis (Fig. 10.5) used the combined measurements from the UKP and Golo adult mandibular Dorcopsis dentitions. Between the three tests performed, they all display a significant separation of the $D$. atrata and D. luctuosa samples, thus indicating that these two may be ruled out as possibilities for identification. However, the significant overlap of the archaeological samples with $D$. hageni and $D$. muelleri in all three tests would seem to indicate that the source population for the extinct Gebe wallaby is likely to have been from one of these two species. D. muelleri is more likely when biogeographic distributions are considered. D. muelleri is broadly distributed across the Bird's Head and the offshore islands of Misool, Japen, and Salawati (Flannery 1995a:79-80), whereas D. hageni is restricted to the northern fringes of New Guinea and absent from the Bird's Head (Flannery 1995b:144-145). 

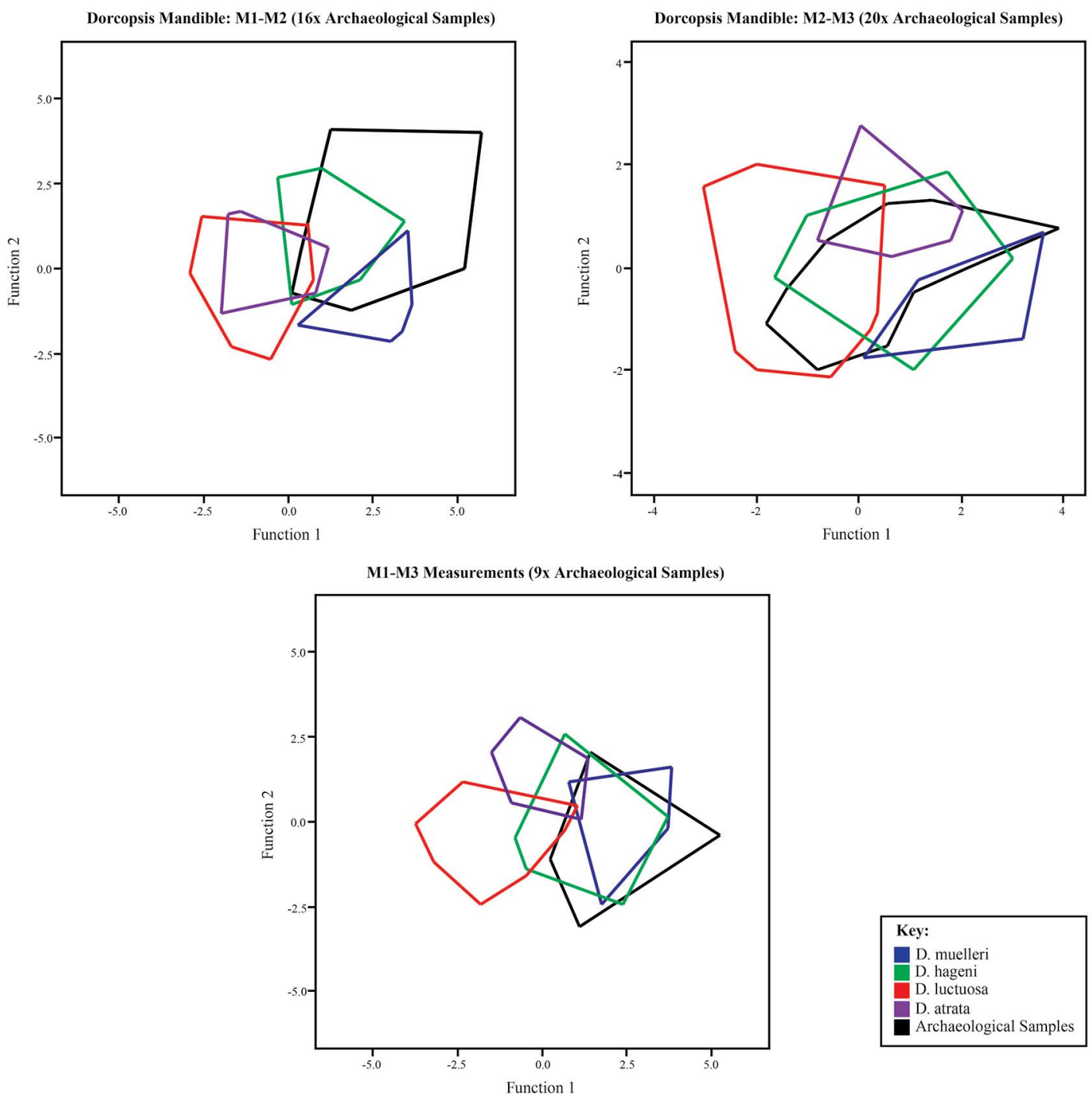

Figure 10.5 Three tests of Discriminant Function Analysis for the molar measurements (max. length, anterior and posterior breadths) for the Golo and Um Kapat Papo samples and those of four extant species of Dorcopsis.

Source: Jennifer R. Hull.

\section{Tanjung Pinang, Morotai Island}

Only 213 bone fragments were recovered from Tanjung Pinang, with phalanger (MNI: 6; NISP: 30) and Osteichthyes and Elasmobranchii (MNI: 6; NISP: 50) being the most numerous; two families and one sub-class were identifiable: Lethrinidae, Scaridae, and Elasmobranchii. Phalanger occurs consistently throughout the upper spits to a depth of $45-50 \mathrm{~cm}$, and then decreases until it ceases to occur $80-85 \mathrm{~cm}$. Only long bone fragments were found, with no cranial elements. No Dorcopsis bones were found at Tanjung Pinang, and there is no evidence for wallabies ever existing on Morotai. Some bat, snake, lizard, and rodent remains were recovered throughout the archaeological sequence, but these were most likely incidental introductions as part of an accumulating natural death assemblage. 


\section{Daeo Caves 1 and 2, Morotai Island}

Of the 16 fragments of bone recorded from Daeo Cave 1, two rodents, one bat, and four fish fragments were identified. In Daeo Cave 2, phalanger and rodents comprised the largest proportion of the assemblage, with MNIs of 33 and 37 respectively. Also present were snakes, lizards, bats, and an unidentified intermediate-sized mammal. The highest number of phalanger remains in any given spit was 28 , at $20-25 \mathrm{~cm}$, with NISPs of 23 and 21 at 35-40 and 30-35 cm respectively. Small numbers of phalanger continued to $75-80 \mathrm{~cm}$, where they ceased. The date of 16,767-15,889 cal. BP on a Turbo marine shell operculum from the $60-65 \mathrm{~cm}$ level in Daeo 2 (ANU 9450) thus overlaps with the oldest phalanger remains, and potentially establishes their presence on Morotai during the Late Pleistocene.

The rodent dentition from Daeo 2 (Fig. 10.6) has tooth dimensions significantly larger than any of the potentially introduced Rattus species, supporting the view of Flannery et al. (1995) that it was most likely the endemic Rattus morotaiensis. These sole cranial elements of rodent in the assemblage are from Squares E4-E5 at 10-15 cm, and hence postdate the C14 date of 6463-6194 cal. BP (ANU 9452).
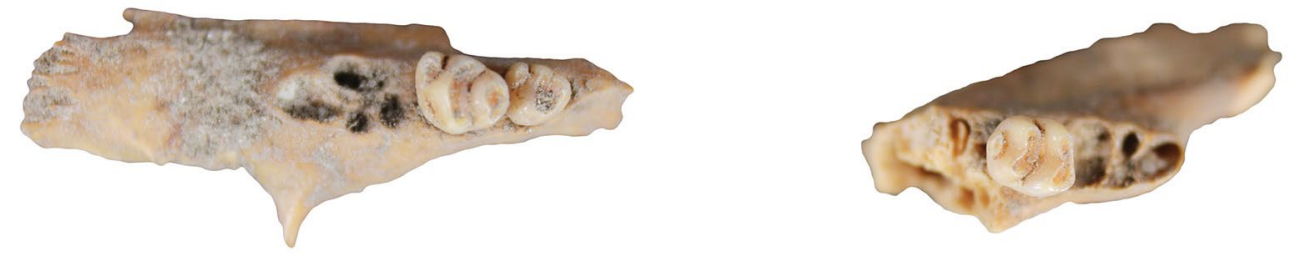

$\mathbf{C M}$

Figure 10.6 A murid rodent right mandible and left maxilla from Daeo Cave 2, E4-E6, 10-15 cm. Source: Jennifer R. Hull.

Fish bones in Daeo 2 were confined between 20 and $45 \mathrm{~cm}$, but do not occur in very large numbers. The most frequent were Scaridae (NISP: 8), Serranidae (NISP: 6) and Belonidae (NISP: 6).

\section{Gua Siti Nafisah, Halmahera Island}

Of the 6698 recovered bone fragments from Siti Nafisah, 5488 were identifiable. By far the largest proportion were bats (NISP: 5060), of which 350 cranial fragments could be identified to family or higher. This included the two genera Hipposiderus and Miniopterus, and the species Rhinolophus euryotis (Fig. 10.7).

With the exception of bats, the major taxa represented in Siti Nafisah were phalanger (MNI: 7; NISP: 111), Muridae (MNI: 4; NISP: 13), $\operatorname{dog}$ (MNI: 3; NISP: 6), Dorcopsis (MNI: 3; NISP: 34), pig (NISP: 7), and bandicoot (MNI: 1; NISP: 2). The dog remains were mainly metacarpals from spits A to A4, with a single metacarpal in C1. Three Dorcopsis incisors were submitted for C14 dating, but contained insufficient collagen. 


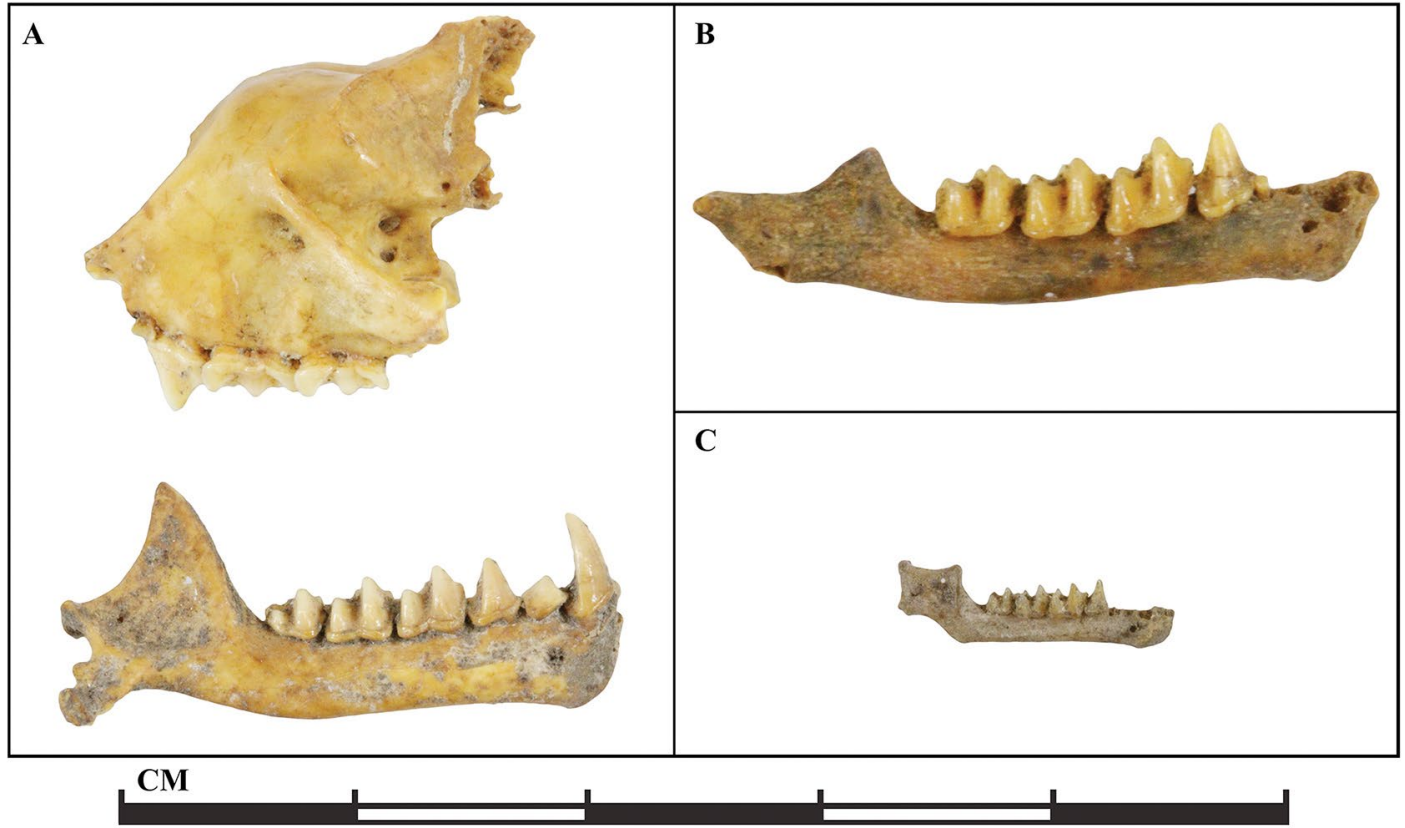

Figure 10.7 Cranial elements of Hipposideros (A), Rhinolophus euryotis (B), and Miniopterus (C) from Gua Siti Nafisah.

Source: Jennifer R. Hull.

Two of the pig bones came from F7 Layer D1 (an ulna) and J10 Layer C2 (a humerusFig. 10.8). Both show evidence of butchery and were sent to the ANU AMS Radiocarbon Laboratory for C14 testing (Table 1.1). The humerus produced a date of 1299-1187 cal. BP, but due to very low magnesium and percentage yield this date may be tenuous. The ulna produced a slightly earlier date of 1825-1699 cal. BP. Both adult and juvenile pigs were present in the site.

Other taxa represented at Siti Nafisah include reptile (NISP: 33), snake (NISP: 45), and Osteichthyes (NISP: 142), the latter including Scaridae and Labridae.

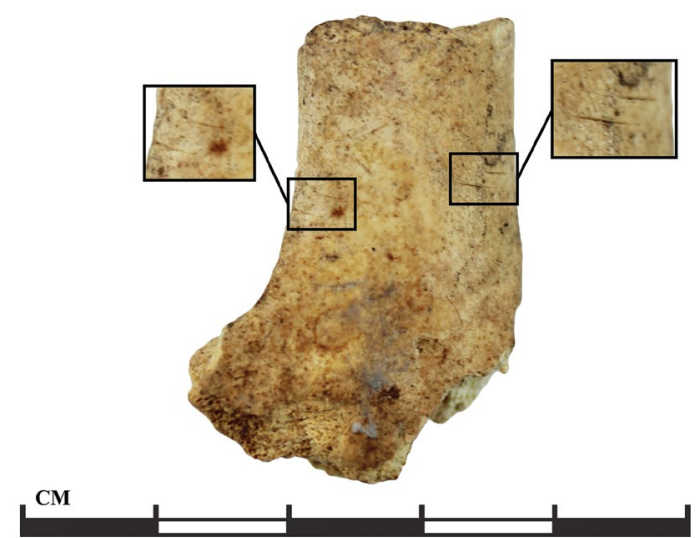

Figure 10.8 Pig distal humerus (right) exhibiting cut marks on the lateral margin, from Gua siti Nafisah, J10, Layer $\mathrm{C}$.

This specimen has been directly C14 dated to 1825-1699 cal. BP (S-ANU 63339).

Source: Jennifer R. Hull.

\section{Uattamdi, Kayoa Island}

Of the 1191 bones recorded from Uattamdi, phalanger (NISP: 19) and Muridae (NISP: 5) occur with insignificant numbers of bat, lizard, and snake. However, there are fairly large numbers of pig (NISP: 4) and dog (NISP: 28), listed by square and spit in Table 10.4. Osteichthyes and Elasmobranchii dominate the assemblage, with 150 bones from 13 identified species (Fig. 10.11), with a further 545 being unidentified. Phalanger bones occur consistently throughout the sequence in relatively small numbers, from the surface down to the basal Layer D5. The recovered phalanger remains decreased in number with depth, but so also did most other taxa. 
Table 10.4 Pig and dog bones by layer from Uattamdi 1.

\begin{tabular}{|l|l|l|}
\hline Layer & Pig NISP & Dog NISP \\
\hline A1 & & 3 \\
\hline A2 & & 6 \\
\hline A3 & & 7 \\
\hline A4 & & 10 \\
\hline A5 & & 1 \\
\hline B1 & & 1 \\
\hline B3 & & 1 \\
\hline B5 & & 1 \\
\hline C2 & 1 & \\
\hline C5 & 2 & 1 \\
\hline C6 & 2 & \\
\hline C9 & & 2 \\
\hline Totals & 5 & 33 \\
\hline
\end{tabular}

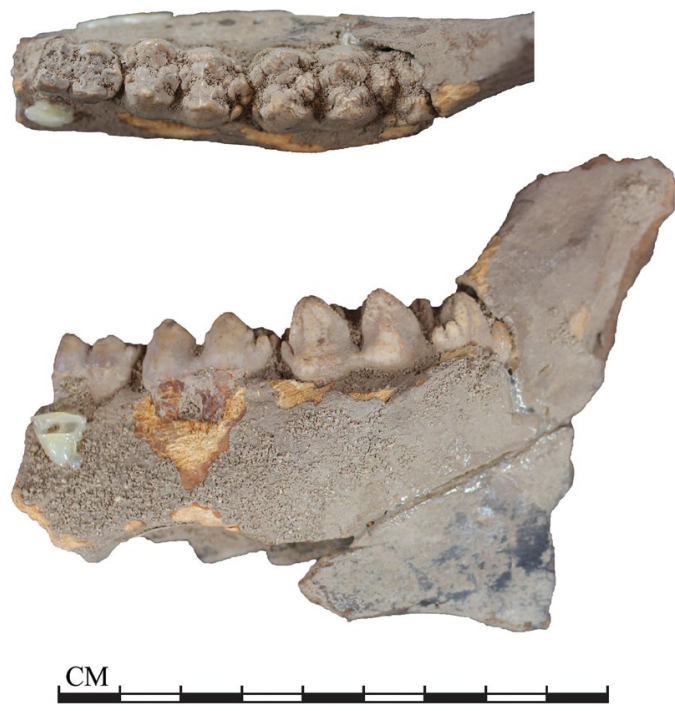

Figure 10.9 A Sus scrofa right mandible recovered from Layer $C 6$ in Uattamdi, directly C14 dated from tooth enamel to 3144-2964 BP (S-ANU 60005, Table 1.1 and Chapter 5).

Source: Jennifer R. Hull.

Two fragments of the right mandible of a young adult pig were found in Uattamdi Layer C6, with an erupted M1-M2 and an M3 still in the process of erupting (Fig. 10.9). Two samples of tooth enamel have been directly dated from this mandible, with a result of c. $3000 \mathrm{cal}$. BP, as discussed in more detail by Rachel Wood in Chapter 5 . This is an important date for establishing a presence of pig at the eastern edge of Island Southeast Asia, almost certainly domesticated in the absence of an indigenous wild pig species in the Moluccas, and during a peak period of Austronesian migration into Oceania. Uattamdi also has dog bones in the younger spits A1 and B5, with two vertebrae in Neolithic spit C9, the latter also potentially dating to c. 3000 BP (Fig. 10.10), although one of the C9 vertebrae sent to the ANU Radiocarbon Dating Laboratory failed the $\% \mathrm{~N}$ screening test (Stewart Fallon, pers. comm., 6 November 2018). The dog bones are predominantly carpals/metacarpals and vertebrae, with a number of refitting tibia fragments from a single context that could have belonged to one individual.

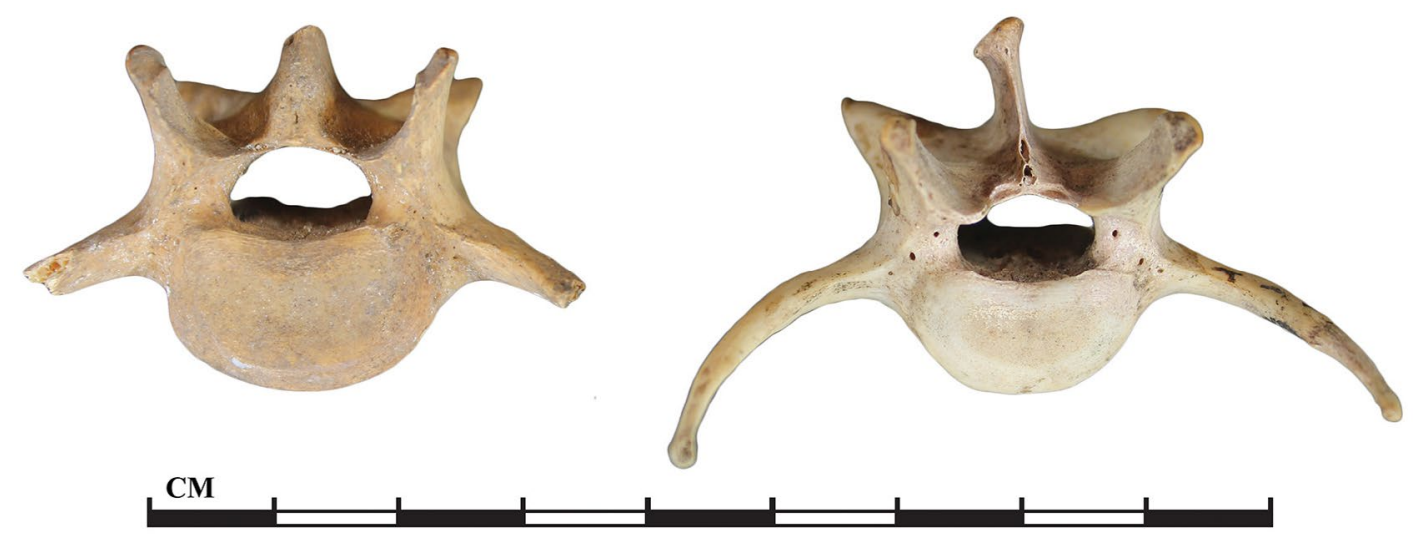

Figure 10.10 A canid vertebra (left) from Uattamdi (E7 A3) compared to a modern comparative Canis lupus familiaris vertebra (right) from the School of Archaeology and Anthropology, ANU.

Source: Jennifer R. Hull. 


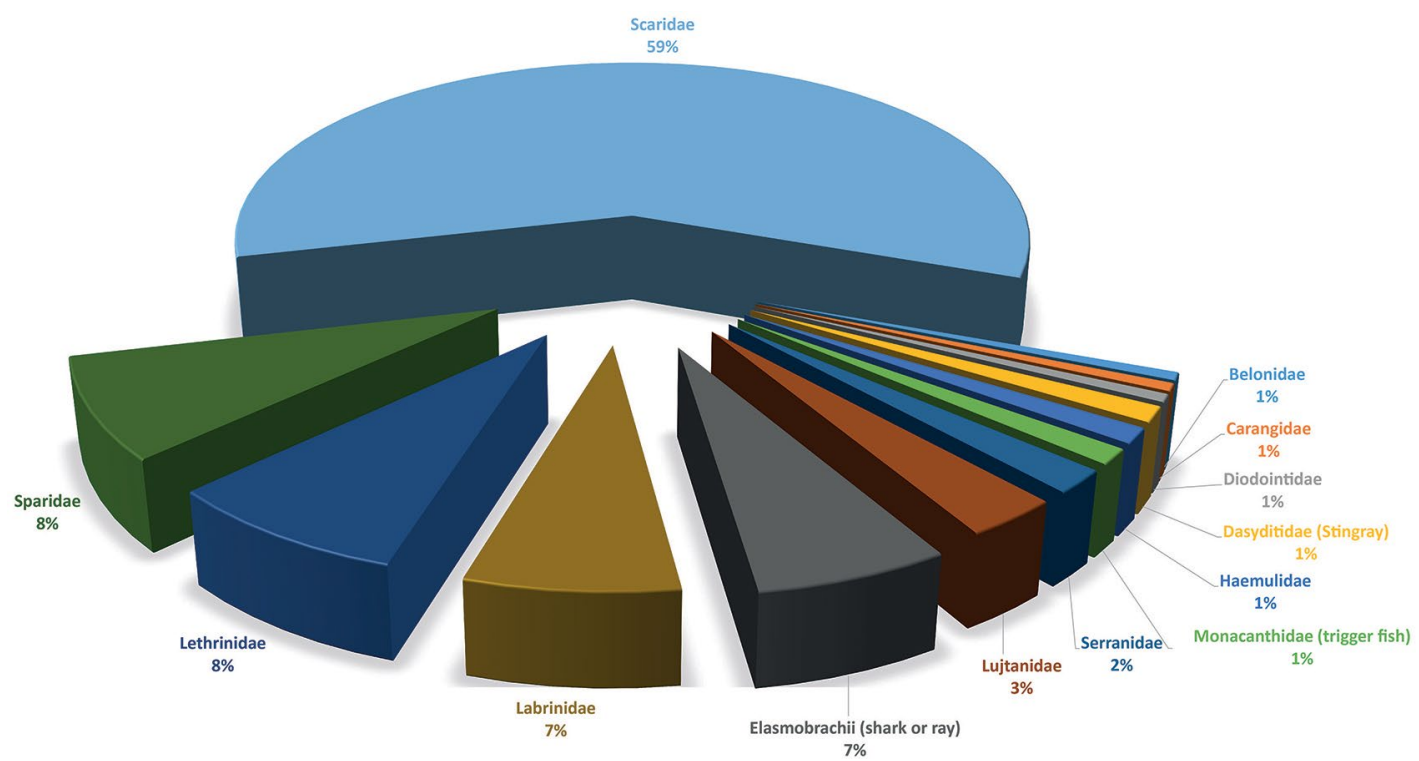

Figure 10.11 Pie chart of identified fish families from Uattamdi, all layers combined.

Source: Jennifer R. Hull.

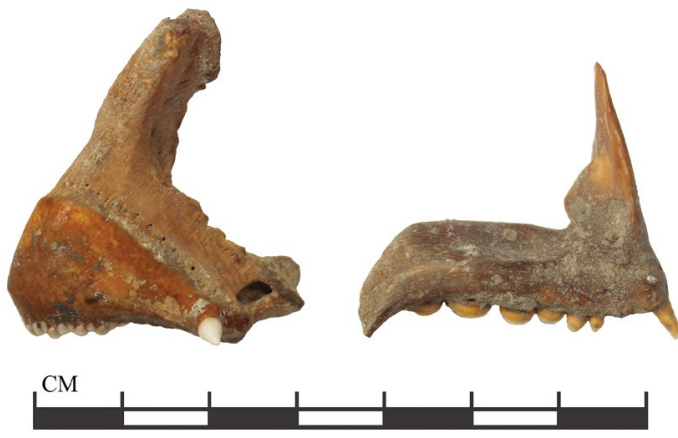

Figure 10.12 Scaridae (left) and Lethrinidae (Monotaxis grandoculis, right) premaxillae from Uattamdi and Daeo Cave 2 respectively.

Source: Jennifer R. Hull.
Scaridae were clearly the dominant family in the identifiable fish remains (Figs 10.11 and 10.12), but this predominance is likely a reflection of differential survivability. Sparidae, Lethrinidae, and Labrinidae were also well-represented. The spit that seemed to have the most varied fish taxa was C3, towards the middle of the stratigraphic sequence, with a charcoal sample dated to 3160-2324 cal. BP (Table 1.1, ANU 7775).

\section{Part 2: Wetef faunal remains (Geoffrey Irwin)}

\section{Animal bone}

Wetef provided a substantial sample of animal bones of anthropogenic origin. These were identified using comparative specimens held at the Anthropology Department, University of Auckland, and the Auckland Institute and Museum. Initial sorting and quantification was done by Robin Milnes and Geoff Irwin and samples were then taken to the University of Sydney for checking by J. Peter White, with assistance from Tim Flannery, then of the Australian Museum.

Most of the bones were broken and some were burned. However, a total of 2521 identifications was made from a total NISP of 7153 , i.e. 35 per cent. Of these identifications, 38.6 per cent were macropod and 26 per cent were phalanger. In both these animals all major bones were present, so we could see no evidence of selective transport or butchering, and both animals could have existed in a wild state on Gebe Island. There were bones of juvenile animals, including 
some small enough to be pouch young. The size range of macropod bones varied considerably, implying sexual dimorphism common among Dorcopsis sp., at least as far as the postcranial skeleton is concerned (see comment by Jennifer R. Hull on macropod teeth, above).

Other significant components were a range of small fish representing 22.8 per cent of the identified NISP (see below), sea turtle, bat of a size comparable to Pteropus sp., occasional reptiles including snake and varanid, and a few birds. No domestic animals were noted. A low rate of post-cranial bones was identified because the bone was very fragmented. However, our impression was that the unidentified bone was in much the same proportion by species as the bone identified. Summary statistics for total NISP and weights for each animal in Squares K3 and $\mathrm{K} 4$ are shown in Table 10.5 .

Table 10.5 Summary of bone NISP and weight (gm) from Wetef K3-K4.

\begin{tabular}{|c|c|c|c|c|c|c|c|c|c|}
\hline Square & Macropod & Phalanger & Turtle & Bat & Reptile & Fish & Bird & Unident. & Total \\
\hline \multicolumn{10}{|l|}{ NISP } \\
\hline K3 & 265 & 230 & 101 & 36 & 6 & 264 & 8 & 2163 & 3073 \\
\hline K4 & 708 & 425 & 41 & 99 & 25 & 310 & 3 & 2469 & 4080 \\
\hline Total & 973 & 655 & 142 & 135 & 31 & 574 & 11 & 4632 & 7153 \\
\hline \multicolumn{10}{|l|}{ Weight } \\
\hline K3 & 323.5 & 92.4 & 113.6 & 7.8 & 4.3 & 119.5 & 4.3 & 993.2 & 1658.6 \\
\hline K4 & 914.1 & 196.2 & 74.4 & 18.8 & 15.8 & 126.0 & 3.8 & 1236.6 & 2585.7 \\
\hline Total & 1237.6 & 288.6 & 188.0 & 26.6 & 20.1 & 245.5 & 8.1 & 2229.8 & 4244.3 \\
\hline
\end{tabular}

Source: Geoffrey Irwin.

Bone was virtually absent in Layer A, and the very few bones present were probably disturbed from below. A major peak in bone occurred through the levels of Layer B, which continued across the Layer B1/B2 interface. In sharp contrast, only small frequencies of bone occurred through the upper levels of Layer C. However, there was a significant increase in bone in association with the lenses of ash in Layer C2 (Fig. 2.16), dated to 9340-8974 cal. BP (Wk 4624) in the lowest band of ash in Layer C2, at a depth of $175 \mathrm{~cm}$ below the surface. Below this, in upper Layer D, very small quantities continued for another $20 \mathrm{~cm}$, towards an associated C14 age of 12,962-12,626 cal. BP (Wk 4625). Following the deposition of the lower ash, Layer D was sealed from any later disturbance. The bone in upper Layer $\mathrm{D}$ could have been contemporary with this date; however, it is also possible that it was contemporary with the lower ash above, and the small quantity present in the top of Layer $\mathrm{D}$ had been carried down by treadage prior to the deposition of that ash. In either case, it is indicated that bone dated to the Early Holocene in Wetef.

It is interesting that both macropod and phalanger occurred as low in the site as any other animal and nothing could be deduced about their time of arrival. Below the ash at the base of Layer C, the deposit was wet and it is considered that any bone formerly in Layer D had been lost through attrition. This is similar to the case of Pamwak Cave on Manus (Fredericksen et al. 1993). If Dorcopsis was a translocated species from Misool near the Bird's Head of New Guinea, as suggested in Flannery et al. (1998), it was brought to Gebe no later than the Early Holocene. Dorcopsis was extirpated in Maluku in recent prehistory after the abandonment of Golo and Wetef caves.

Four samples of Dorcopsis bone from Wetef were submitted to the Rafter Radiocarbon Laboratory for AMS dating. Two samples from Layer D were found to be in a highly degraded condition and no collagen had survived. Results for the two samples dated are shown in Table 2.5. Sample NZA 8369 was collected from K4, Layer A. It was subjected to amino acid analysis and the 
sample was found to be moderately well to somewhat poorly preserved. The C14 age is cal. 906-570 BP. Sample NZA 8387, from K4 Layer B, was found to be extremely poorly preserved, but it produced an age of 6487$6182 \mathrm{cal}$. BP, which accords fairly well with the two wallaby bone direct dates of $8000-7500$ cal. BP (discussed above) from Golo Cave.

Calculations of MNI for macropod and phalanger, based on mandibles, are shown in Table 10.6, and the details of NISP and weight of bone by $10 \mathrm{~cm}$ levels for $\mathrm{K} 3$ and $\mathrm{K} 4$ are shown in Tables 10.7-10.10.
Table 10.6 Macropod and phalanger MNI from Wetef.

\begin{tabular}{|l|c|c|c|c|}
\hline & \multicolumn{2}{|c|}{ Macropod } & \multicolumn{2}{c|}{ Phalanger } \\
\hline & $\mathbf{L}$ & $\mathbf{R}$ & $\mathbf{L}$ & $\mathbf{R}$ \\
\hline K3 & 16 & 10 & 17 & 15 \\
\hline K4 & 24 & 23 & 25 & 37 \\
\hline Total & 40 & 33 & 42 & 52 \\
\hline
\end{tabular}

Source: Geoffrey Irwin.

\section{Fish bone from Wetef}

Fish bones were abundant in the site (NISP $=574$, Table 10.11). They survived to a depth of $200 \mathrm{~cm}$, as deep as the bones of any other animal; however, the distribution of fish was different. There was a major peak in the frequency of all bone through Layer B, but in Layer C1 bone was sparse. There was a clear increase again in Layer C2, but fishbone remained rare. Layer B accounted for 93.4 per cent of all fishbone with only 3.2 per cent and 0.6 per cent respectively in Layers $\mathrm{C}$ and $\mathrm{D}$. These results may suggest that fishing became important at Wetef when rising sea levels approached modern levels.

Some 26 per cent $(n=153)$ of the fish bones were identified to family level using comparative collections at the Anthropology Department, University of Auckland, with assistance from Simon Duff and advice from Melinda Allen. Some 11 families were present, but three families made up 75 per cent of identified specimens: Holocentridae (Soldierfishes and Squirrelfishes) 26 per cent, Muraenidae (Moray eels) 27 per cent, and Scaridae (Parrotfish) 23 per cent (Table 2.11). With one exception, represented by a single bone of Barracuda (Sphyraenidae), all families were associated with inner or outer reef habitats. The sample size is inadequate to represent the range of fishing behaviour at the site. However, ethnographic information from Pacific contexts indicates a variety of methods for capture of these fish and one method, common to all, was taking by spear.

Table 10.7 Wetef Square K3, bone NISP.

\begin{tabular}{|l|r|r|r|r|r|r|r|r|r|}
\hline Level & Macropod & Phalanger & Bat & Turtle & Reptile & Fish & Bird & Unident & Total \\
\hline $0-10$ & & & & & & & & & \\
\hline $10-20$ & & & & 1 & & & & 2 & 3 \\
\hline $20-30$ & & & & & & & & 7 & 7 \\
\hline $30-40$ & 3 & 7 & 4 & & & 13 & & 71 & 98 \\
\hline $40-50$ & 75 & 55 & 8 & 32 & 1 & 24 & 6 & 364 & 565 \\
\hline $50-60$ & 94 & 90 & 14 & 56 & 2 & 80 & & 494 & 830 \\
\hline $60-70$ & 7 & 24 & 6 & & & 95 & & 228 & 360 \\
\hline $70-80$ & 30 & 26 & 1 & & 2 & 16 & & 347 & 422 \\
\hline $80-90$ & 11 & 10 & 3 & 12 & 1 & 24 & 2 & 285 & 348 \\
\hline $90-100$ & 10 & 13 & & & & 7 & & 200 & 230 \\
\hline $100-110$ & 6 & 2 & & & & 2 & & 33 & 43 \\
\hline $110-120$ & 1 & & & & & & & 7 & 8 \\
\hline
\end{tabular}




\begin{tabular}{|c|c|c|c|c|c|c|c|c|c|}
\hline Level & Macropod & Phalanger & Bat & Turtle & Reptile & Fish & Bird & Unident & Total \\
\hline $120-130$ & 1 & 1 & & & & 1 & & 14 & 17 \\
\hline $130-140$ & 3 & & & & & 1 & & 12 & 16 \\
\hline $140-150$ & 3 & 2 & & & & 1 & & 25 & 31 \\
\hline $150-160$ & 12 & & & & & & & 32 & 44 \\
\hline $160-170$ & 7 & & & & & & & 21 & 28 \\
\hline $170-180$ & 2 & & & & & & & 19 & 21 \\
\hline \multicolumn{10}{|l|}{ 180-190 } \\
\hline $190-200$ & & & & & & & & 2 & 2 \\
\hline
\end{tabular}

Source: Geoffrey Irwin.

Table 10.8 Wetef Square K3, bone weight (gm).

\begin{tabular}{|c|c|c|c|c|c|c|c|c|c|}
\hline Level & Macropod & Phalanger & Bat & Turtle & Reptile & Fish & Bird & Unident & Total \\
\hline \multicolumn{10}{|l|}{$0-10$} \\
\hline $10-20$ & & & & 3.2 & & & & 4.7 & 7.9 \\
\hline $20-30$ & & & & & & & & 3.7 & 3.7 \\
\hline $30-40$ & 3.5 & 2.7 & 0.4 & & & 1.5 & & 20.1 & 28.2 \\
\hline $40-50$ & 107.0 & 26.6 & 2.2 & 38.7 & 0.8 & 15.1 & 3.5 & 205.2 & 399.1 \\
\hline $50-60$ & 88.4 & 28.0 & 3.2 & 59.1 & 1.8 & 32.4 & & 231.2 & 444.1 \\
\hline $60-70$ & 5.8 & 10.5 & 1.4 & & & 27.8 & & 82.1 & 127.6 \\
\hline $70-80$ & 41.2 & 12.7 & 0.2 & & 0.9 & 3.4 & & 150.5 & 208.9 \\
\hline $80-90$ & 17.0 & 4.6 & 0.4 & 12.6 & 0.8 & 31.8 & 0.8 & 113.9 & 181.9 \\
\hline $90-100$ & 12.6 & 5.6 & & & & 2.5 & & 90.8 & 104.8 \\
\hline $100-110$ & 6.7 & 0.8 & & & & 0.9 & & 14.9 & 23.3 \\
\hline $110-120$ & 0.6 & & & & & & & 3.6 & 4.2 \\
\hline 120-130 & 6.6 & 0.3 & & & & 2.5 & & 5.0 & 14.4 \\
\hline $130-140$ & 6.4 & & & & & 1.2 & & 10.1 & 17.7 \\
\hline 140-150 & 1.8 & 1.8 & & & & 0.4 & & 15.3 & 19.3 \\
\hline $150-160$ & 19.9 & & & & & & & 18.0 & 37.9 \\
\hline 160-170 & 5.6 & & & & & & & 8.2 & 13.8 \\
\hline 170-180 & 1.0 & & & & & & & 7.0 & 8.0 \\
\hline \multicolumn{10}{|l|}{ 180-190 } \\
\hline 190-200 & & & & & & & & 6.1 & 6.1 \\
\hline
\end{tabular}

Source: Geoffrey Irwin.

Table 10.9 Wetef Square K4, bone NISP.

\begin{tabular}{|l|r|r|r|r|r|r|r|r|r|}
\hline Level & Macropod & Phalanger & Bat & Turtle & Reptile & Fish & Bird & Unident & Total \\
\hline $0-10$ & & & & & & & & & \\
\hline $10-20$ & 1 & 2 & 3 & & & 7 & & & 13 \\
\hline $20-30$ & & & & & & 18 & 10 & 28 \\
\hline $30-40$ & 33 & 17 & 2 & 1 & & 10 & & 198 & 261 \\
\hline $40-50$ & 129 & 11 & 27 & 6 & 38 & 3 & 378 & 894 \\
\hline $50-60$ & 105 & 100 & 15 & 7 & 2 & 94 & & 304 & 627 \\
\hline $60-70$ & 73 & 43 & 24 & 2 & 1 & 54 & 428 & 625 \\
\hline $70-80$ & 66 & 57 & 5 & 4 & 6 & 24 & & 346 & 508 \\
\hline $80-90$ & 45 & 36 & 24 & & 9 & 20 & & 314 & 443 \\
\hline $90-100$ & 25 & 13 & 9 & & 1 & 19 & & 174 & 259 \\
\hline
\end{tabular}




\begin{tabular}{|c|c|c|c|c|c|c|c|c|c|}
\hline Level & Macropod & Phalanger & Bat & Turtle & Reptile & Fish & Bird & Unident & Total \\
\hline $100-110$ & 3 & & & & & 6 & & 18 & 27 \\
\hline $110-120$ & & & & & & 3 & & 13 & 16 \\
\hline $120-130$ & 1 & & & & & 1 & & 23 & 26 \\
\hline $130-140$ & 4 & & & & & 1 & & 19 & 24 \\
\hline $140-150$ & 2 & 1 & & & & 1 & & 17 & 21 \\
\hline $150-160$ & 8 & 1 & & & & 5 & & 43 & 57 \\
\hline $160-170$ & 16 & 4 & & & & & & 77 & 101 \\
\hline $170-180$ & 20 & 2 & & & & & & 84 & 106 \\
\hline $180-190$ & 1 & 1 & & & & 2 & & 2 & 6 \\
\hline $190-200$ & 2 & 2 & & & & 7 & & 17 & 28 \\
\hline $200-210$ & 1 & & 1 & & & 1 & & 3 & 6 \\
\hline $210-220$ & & & & & & & & 1 & 1 \\
\hline
\end{tabular}

Source: Geoffrey Irwin.

Table 10.10 Wetef Square K4, bone weight (gm).

\begin{tabular}{|c|c|c|c|c|c|c|c|c|c|}
\hline Level & Macropod & Phalanger & Bat & Turtle & Reptile & Fish & Bird & Unident & Total \\
\hline \multicolumn{10}{|l|}{$0-10$} \\
\hline $10-20$ & 2.3 & 1.2 & 0.3 & & & 1.8 & & & 5.6 \\
\hline $20-30$ & & & & & & 1.5 & & 2.6 & 4.1 \\
\hline $30-40$ & 45.1 & 7.2 & 2.3 & 2.9 & & 12.8 & & 67.2 & 137.5 \\
\hline $40-50$ & 400.6 & 57.7 & 3.2 & 54.8 & 4.3 & 25.0 & 3.8 & 201.5 & 751.2 \\
\hline $50-60$ & 94.0 & 41.5 & 1.9 & 12.2 & 2.9 & 42.8 & & 162.6 & 356.9 \\
\hline $60-70$ & 98.0 & 16.0 & 3.1 & 3.1 & 0.6 & 15.9 & & 209.8 & 346.5 \\
\hline $70-80$ & 85.6 & 31.2 & 0.7 & 1.4 & 4.7 & 5.9 & & 169.4 & 298.9 \\
\hline $80-90$ & 42.4 & 19.6 & 4.6 & & 2.5 & 6.3 & & 149.7 & 226.1 \\
\hline $90-100$ & 45.3 & 16.0 & 1.2 & & 0.8 & 4.5 & & 84.1 & 151.9 \\
\hline 100-110 & 3.4 & & & & & 1.6 & & 16.7 & 22.2 \\
\hline $110-120$ & & & & & & 0.6 & & 13.1 & 13.7 \\
\hline $120-130$ & 2.3 & & 0.9 & & & 0.6 & & 26.0 & 29.8 \\
\hline 130-140 & 10.5 & & & & & 0.8 & & 8.7 & 20.0 \\
\hline 140-150 & 8.3 & 0.8 & & & & 0.5 & & 14 & 23.6 \\
\hline $150-160$ & 11.1 & 0.7 & & & & 1 & & 19.8 & 32.5 \\
\hline $160-170$ & 27.9 & 2.1 & 0.4 & & & & & 42.6 & 72.8 \\
\hline $170-180$ & 31.7 & 1.5 & & & & & & 41.4 & 74.8 \\
\hline 180-190 & 1.9 & & & & & 1 & & 0.7 & 3.6 \\
\hline $190-200$ & 1.7 & 0.7 & & & & 1.7 & & 4.5 & 8.6 \\
\hline $200-210$ & 1.3 & & 0.1 & & & 1.1 & & 2.2 & 4.7 \\
\hline $210-220$ & & & & & & & & 0.1 & 0.1 \\
\hline
\end{tabular}

Source: Geoffrey Irwin. 


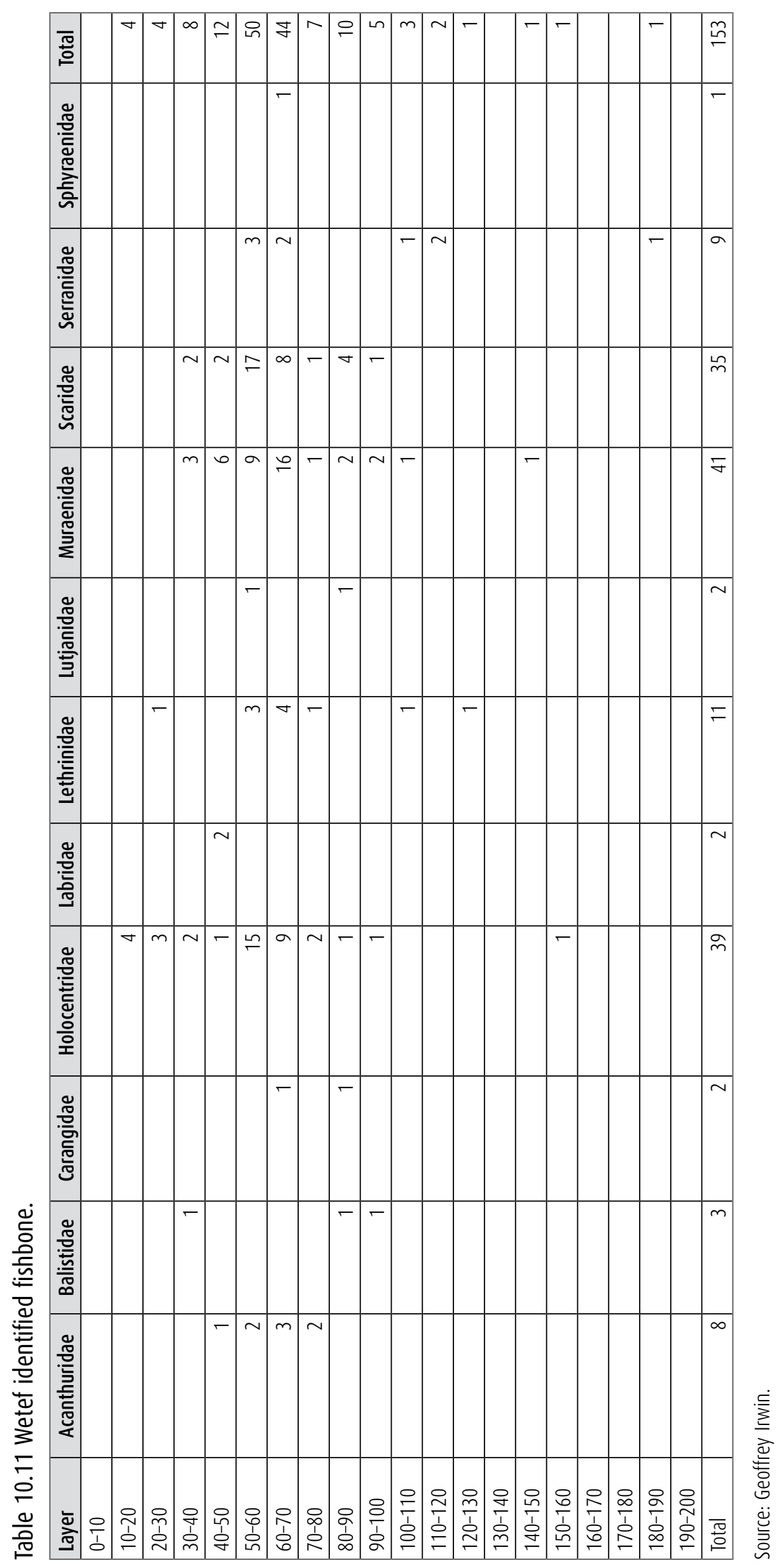




\section{Zooarchaeological discussion and conclusions for Parts 1 and 2}

The taphonomic processes visible in the faunal assemblages of the seven sites (excluding Wetef) analysed by Jennifer R. Hull at ANU varied considerably. The two Golo trenches on Gebe showed extensive subaerial weathering as well as significantly high concretions of calcium carbonate, often to the point of obscuring the remains. Whilst there are some examples of burning and butchery, they are not particularly common. The Dorcopsis remains are predominantly in the adult and mature adult age ranges, but there are some juveniles and sub-adults. The age distribution would suggest that a wild breeding population of Dorcopsis previously existed on Gebe Island. This would also seem to indicate a targeting of older animals, but not exclusively.

The sequence of faunal remains in these two Golo trenches does not descend as far as bedrock, a situation quite different from that with respect to marine shell, which does extend down to bedrock. This may provide an indication of severe taphonomic processes that have caused the complete destruction of bone below c. $1 \mathrm{~m}$ depth. This is evident in the extremely poor condition of the corroded bone fragments recovered from the deepest bone-bearing layers.

The Dorcopsis tooth enamel C14 dates from the lowest recorded levels with bone, at 75-80 and $80-90 \mathrm{~cm}$, suggest that wallabies were definitely present on Gebe by $8000 \mathrm{BP}$, a date confirmed by one of the direct dates on wallaby bone from Wetef. Dogs and pigs are likely of Neolithic antiquity, after $3500 \mathrm{BP}$, and these introductions might have been partly responsible for the disappearance of Dorcopsis from Gebe by 906-570 cal. BP (Wetef rockshelter, NZA 8369).

Um Kapat Papo on Gebe revealed a very different taphonomic picture from Golo. There was far less disturbance, weathering, and calcium carbonate concretion in this site. As in Golo, evidence for butchery indicates that wallabies were eaten, although the full diet was probably dominated by fish, especially in the younger levels. No pig bones were found in UKP, and only a single fragment is likely to be dog, from Layer 3, 20-25 cm, thus relatively low and early in the sequence, which could suggest disturbance.

On Morotai Island, Tanjung Pinang exhibits low levels of disturbance and weathering, with no evidence of butchery and no presence of Dorcopsis. Phalanger was the dominantly recovered taxon. Fish were also a highly targeted resource, with specimens of Elasmobranchii, Scaridae, and Lethrinidae recovered. Daeo Cave 2 exhibited more disturbance and burning than Tanjung Pinang, but still with low levels of weathering.

Siti Nafisah on Halmahera is another fairly stable site with very little evidence of weathering or disturbance in the bone assemblage. Here, the burnt bones are consistent with inadvertent burning within fires associated with cooking activities, and there is more evidence of butchery than in some of the other sites. Fragmentation at this site was also less, and a much larger portion of the assemblage was taxonomically identifiable than in the other sites. The vast majority of the bones were of bat (4700/5081 fragments), unsurprising given the site is a cave, but whether bats were eaten is unclear. Aside from bats, the assemblage was dominated by phalanger, Dorcopsis, and reptiles (including snakes). Some dog and pig bones occur in the upper Neolithic layers. As on Gebe, it appears likely that the introduction of pig and dog may have contributed to the disappearance of the Dorcopsis from Halmahera. Of the fish, only Scaridae and Labridae could be identified.

The Neolithic site at Uattamdi exhibits some disturbance, sporadic evidence of burning and low levels of weathering. This site has the greatest predominance of fish bones, with the largest range of species (13) identified, with Scaridae the dominant family. Phalanger was the most common mammal, accompanied by pig and dog. The pig bones occur in the Neolithic layers in the cave, whereas dog bones occur almost throughout the sequence, which commenced around 3300 BP. 
The indicators of weathering and site instability were thus highest on Gebe, whereas the Morotai and Halmahera sites had better preservation. Butchery evidence showed that phalanger, Dorcopsis (except on Morotai) and other taxa were being targeted as food resources. The Neolithic introductions of pig and dog roughly coincided with the decrease in Dorcopsis in the sequence, suggesting a possible link between the two trends.

The discriminant function analysis undertaken on the dentitions of Dorcopsis from Golo and Um Kapat Papo indicated that the Northern Moluccan archaeological samples were closely correlated with the Papuan D. muelleri and D. hageni dentitions in the Australian Museum, as previously noted by Flannery et al. (1998). The study was performed on the M1-M3 of nine archaeological samples. However, two other discriminant function tests (Fig. 10.5) with larger samples sizes of 16 (M1-M2) and 20 (M2-M3) teeth had a more pronounced overlap with D. hageni. Groves and Flannery (1989) described both $D$. muelleri and D. hageni as cranially and dentally very close in morphology and size. The only significant differences were in biogeographical range, with muelleri being present in the lowlands of West Papua as well as the islands of Misool, Salawati, and Yapen, and hageni in the lowlands of northern New Guinea. The current biogeographic distributions of the two species as recorded by Groves and Flannery (1989), and the statistical analyses by Flannery et al. (1998), led to the conclusion that the extinct population on Gebe Island was D. muelleri, potentially sourced from Misool or the mainland of New Guinea. The statistical analyses performed here, whilst somewhat inconclusive, seem to have a similar result. However, the larger dental sample analysed size here reveals considerable overlap between D. muelleri and D. hageni; as such, more data may be required to distinguish them conclusively.

The information from Wetef, analysed separately in Auckland, complements that from Golo fairly tightly. Both sites have ample evidence for human exploitation of Dorcopsis wallabies, phalanger cuscuses, and fish during the Holocene, but what happened prior to this? The wallabies on Gebe and Halmahera appear to be relatively unspeciated with respect to the other New Guinea extant species, and this implies a relatively recent date of introduction, in evolutionary terms. But were the introductions by natural means during periods of low sea level, or were they by human intention? Without older bone assemblages from the Northern Moluccas this mystery might never be solved fully, although analysis of ancient DNA from Moluccan and New Guinea archaeological samples could be very informative in the future. The same applies to the bones of the pigs and dogs, both species intricately involved in the history of human migration in Island Southeast Asia (Bellwood and White 2005; Oskarsson et al. 2011).

\section{Part 3: A Late Pleistocene/Early Holocene shell midden sample from Golo Cave (Katherine Szabó and Annette Oertle)}

Some of the oldest archaeological evidence for marine mollusc exploitation in the island AsiaPacific region is evidenced by material excavated from Golo Cave. Aspects of the Golo Cave molluscan shell assemblage have already been well-reported via publications on the rich worked shell component. This includes the flaking of large, robust Turbo marmoratus opercula in the lowest levels of the site (Szabó et al. 2007), the repurposing of Scutellastra flexuosa limpets from the shell midden as scrapers in the Pleistocene (Koppel 2010; Szabó and Koppel 2015), and the deliberate shaping of Nautilus shell fragments also recovered from the lowest layers of the Golo deposits (Szabó 2013; Parkinson 2016). Although some details of the shell midden assemblage have been discussed as part of the presentation of data on the worked shell, including the chapter on the worked shell included in this volume, the contents and nature of the shell midden have only received partial summary in Szabó (2005). 
A detailed taphonomic analysis of the Golo Cave shell midden sample, which also addresses issues of midden formation and transformation processes, is ongoing and will be published in due course. Here, we present the broad structure and nature of the Golo Cave shell midden from the available sample, particularly addressing issues of species representation and the changing nature of the molluscan assemblage through time. Key questions of interest include:

a. What sorts of molluscan resources were being transported back to Golo Cave?

b. What do these resources tell us about changes in nearby littoral environments through time?

c. What do they tell us of the utilisation of molluscan resources by Gebe human populations?

d. What are the relationships between the midden shell and the worked shell in Golo Cave?

One of the most intriguing features of the faunal record at Golo Cave is the absence of bone in the mid and lower portions of the site, despite the presence of largely well-preserved shell midden at all levels. Radiocarbon dates on midden and worked shell from the lower half of the sequence indicate that the molluscan material is not intrusive (barring the exceptional incongruous dates of the adzes manufactured on old shell). As is clearly visible in Table 2.2, shell midden is found throughout all levels of the excavated sequence, whereas negligible bone occurs below a depth of $1 \mathrm{~m}$. As with the bone, shell midden densities peak between 30 and $60 \mathrm{~cm}$ depth. However, while bone densities fall off sharply below $-70 \mathrm{~cm}$ depth, the shell midden continues and is never represented in the M5 sample counted in Table 2.2 by less than $325 \mathrm{gm}$ in a $10 \mathrm{~cm}$ spit. Whilst there could reasonably be taphonomic factors at play, as discussed above, it is hard to conceive of a taphonomic process that would eradicate all traces of a bone assemblage and yet leave the associated shell in readily identifiable condition at all levels.

Given the continuity in the presence of shell throughout the Golo sequence, an alternative would have been to look for reflections of changes in the broader landscape that could have impacted upon resource availability. The Pleistocene/Holocene transition doubtless had impacts upon the terrestrial and inshore habitats surrounding Golo Cave, and the introduction of exotic fauna by humans - whether wild or domesticated - would also have changed landscapes and interspecies relationships in both direct ways (e.g. the potential use of dogs for hunting) and indirect ways (e.g. vegetation and habitat change associated with land clearance). Additionally, as new fauna (and likely flora) were introduced into the diet and daily practices, the whole structure of the subsistence economy would have readjusted. Since shell is the only faunal material to span the whole Golo sequence, it could have provided some insight. Unfortunately, the extant shell midden sample available for analysis only covers the lower half of the site from $120 \mathrm{~cm}$ downwards, meaning that there is effectively no overlap with the vertebrate assemblage. Further details on the nature of the sample, and the sorts of analysis this enabled, are provided here.

\section{Background to the sample}

As briefly outlined in Chapter 9, the only complete shell midden sample retained for analysis derived from the lower half of Square M4, although sporadic samples of shell from other squares, as well as the mid-portions of M4, were retained to provide samples for radiocarbon dating. These latter radiocarbon samples tended to focus on larger, more robust species such as Turbo setosus and the opercula of this species as well as T. argyrostomus. Both the weight and the selective sampling of these shells would doubtless skew results if included, so they have been omitted from all calculations where they do not form part of the M4 shell midden assemblage from an uppermost depth of $140 \mathrm{~cm}$. Only at a depth of $140 \mathrm{~cm}$ downwards does the M4 midden sample diversify and include all recovered taxa. 
The Golo radiocarbon chronology (see Table 1.1) suggests that the zone around 130-140 cm dates to the Pleistocene/Holocene transition, taking in both the last stages of the terminal Pleistocene and the very onset of the Holocene. Thus, the shell midden assemblage presented and considered here is dominated by Late Pleistocene material with the possible inclusion of some Early Holocene shell in the uppermost spits included in the sample. The on-site spit weights recorded for midden shell from Square M5 (see Table 2.2) clearly show the highest totals for shell by some margin to be derived from the upper Holocene deposits between approximately 20 and $70 \mathrm{~cm}$ (Fig. 10.13). Although we assume these dense midden deposits were also present in the adjoining M4, their absence from the transported sample means that nothing can be said about the potential composition.

The absence of shell midden samples from above $140 \mathrm{~cm}$ necessarily means that we cannot speak to potential changes, or indeed stability, in littoral environments and/or human behaviour through time. However, we do have a valuable sample in terms of the overall faunal sequence: shell is consistently represented where bone is absent from the record. While this pattern comes across as anomalous, it is not without precedent in the region, and findings from elsewhere in the region will be considered in the Discussion section.

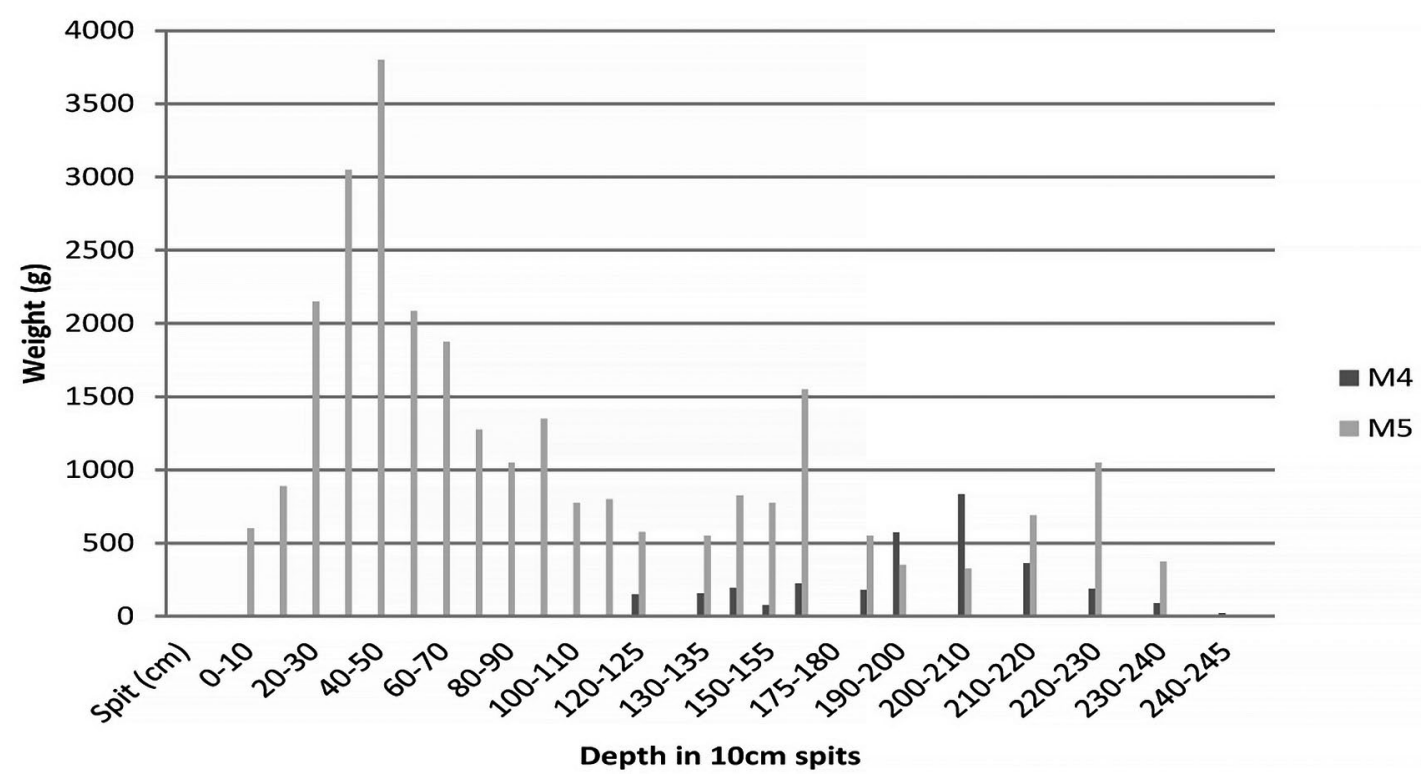

Figure 10.13 Graph to show the relative representation of shell midden (by weight) across spits in Golo Square M4 and M5.

The M5 data are taken from Table 2.2 and the M4 data derive from the research presented here. The M4 weights were recorded for each $5 \mathrm{~cm}$ excavation spit, so have been combined into $10 \mathrm{~cm}$ spit totals here for comparability with the M5 data. It should be noted that some $5 \mathrm{~cm}$ spits between a depth of 145 and $185 \mathrm{~cm}$ are missing from the transported M4 sample (see Table 10.12).

Source: Katherine Szabó and Annette Oertle.

\section{Methods and approaches}

All shell transported back to Australia was analysed by Szabó in 2002/03 and again by Oertle in 2017. Various taxa (e.g. Scutellastra flexuosa and Nautilus sp.) were studied in greater depth separately at different points in investigations of potential shell working (Szabó and Koppel 2015; Parkinson 2016). 
Taxonomic identifications were made to the lowest possible level, but being careful not to assume that fragments with only genus-level identifiable features belonged to common or already identified species. Identifications were made using a wide assortment of text- and webbased resources, as well as the personal shell collection of Szabó. Taxonomy was updated and standardised using the World Register of Marine Species (WoRMS, www.marinespecies.org). Material had been pre-sieved and partially sorted during the bagging process in the field, and no further sieving was undertaken. All size classes of fragment were analysed.

To circumvent any issues of differential fragmentation, the most robust unique non-repeating elements were chosen for each taxon. For bivalves both the left and right hinges were counted, the posterior valve of chiton specimens were counted, and for gastropods the columella edge of the aperture was counted with the exception of all limpets, where the apex was used as the non-repeating element. Given that Golo Cave was excavated in $5 \mathrm{~cm}$ spits with no discernible stratigraphy at the depths represented by the shell sample, MNI values could not be calculated within stratigraphic units. However, a lack of discernible stratigraphy on site does not necessarily mean that different time periods are not represented in the shell sample. Therefore, to avoid inflation of totals, the highest value for either left or right hinges of bivalves within the complete M4 sample was used as the MNI value. This is likely to be an under-representation of occurrences, but will not overestimate numbers. Because the worked shell material was separated, analysed, and reported upon separately, the totals for worked shell objects are not represented in the numbers given here.

During the course of both the 2002/03 and 2017 analyses, running notes were made on the occurrence of various taphonomic indicators. These included the presences of:

a. beach-rolling/post-mortem introduction into the site, as indicated by a muting of surface features and sculpture and the uniform rounding of edges, as well as bioerosion and/or bioadhesions such as barnacles on inner shell surfaces

b. burning, as indicated by a noticeable colour change clearly distinct from staining, or shell recrystallisation clearly visible as a textural change at fracture surfaces

c. hermitting, as indicated by abrasion to the interior of the aperture on gastropods, dragmarks on the outer ventral surface, and other indicators outlined in Szabó (2012)

d. fragmentation, as assessed through a comparison of MNI to NISP totals.

Mention will be made of the noted presence of these indicators where relevant, although they will be dealt with more systematically and comprehensively upon the completion of Oertle's current research into taphonomic variables as they relate to the shell assemblage.

\section{Results of analysis}

A combined total of 49 species of marine gastropod, bivalve, and polyplacophoran (chiton) was identified within the M4 shell midden sample, with a further three taxa identified to higher taxonomic levels (Table 10.12). Aggregated Turbo spp. opercula were quantified as a group, but are not included in the species tallies. Additionally, five species of terrestrial snail were identified and these will be discussed further below. Limited numbers of decapod crustacean and echinoid urchin remains were also recovered, along with greater numbers of plates of large barnacles. These are not reported on here and are the subject of a separate study.

The four most strongly represented species total over 85 per cent of the M4 marine shell midden assemblage as calculated through MNI values. These are the limpet species Cellana radiata comprising 42 per cent, Patelloida striata 19 per cent and Scutellastra flexuosa 10 per cent, as well as the nerite species Nerita plicata comprising a further 15 per cent. Each of these four species 
are associated with hard-shore intertidal habitats, and the majority of the remaining marine molluscan taxa also derive from this zone, including a variety of taxa within the Muricidae and Neritidae families. Bivalves are poorly represented, totalling less than 2 per cent of the marine mollusc assemblage. However, there may be proxies for the presence of further bivalves within the gastropod component.

Species within the Muricidae are predators on other molluscs. They drill holes through the shells of their prey and extract the animal from within. The large variety of muricid species present within the M4 sample, all associated with rocky habitats, suggests that an ample source of food existed in the vicinity of collection. These muricids feed largely on nerites, limpets, barnacles, and other molluscan residents of exposed shorelines (Fiene-Severns et al. 1998), all of which are well represented within the M4 assemblage. However, this group of muricids, often known as 'rock shells', is also known by the common collective name 'oyster drills', as rock oysters are often a favoured prey item (e.g. see Tan 1993; Wright et al. 2018). Although bivalves are poorly represented overall, the best-represented taxon in the M4 sample is the rock oyster Saccostrea sp. Interestingly, it is only represented by right (upper) valves. As left (lower) valves are generally cemented to the substrate (or other shells), on-site extraction/processing of Saccostrea spp. oysters is effective in terms of time and energy, and if any parts of the shell are collected with the animal it tends to be the loose right valve (Szabó, pers. obs.). The sample is too small to make any claims with certainty, but the presence of some right valves of rock oysters, as well as numbers of predators that would inhabit those beds, indicates that oyster beds were in the vicinity of the site at the time of occupation and were exploited. Their presence may be under-represented through a tendency towards point-of-collection processing.

Despite a lack of visible stratigraphy and the presence of only the lowest metre of the M4 sequence in the shell sample, there is clearly visible vertical patterning in the distribution of shell. This is observable in Table 10.12, and is also shown graphically in Figure 10.14. Most of the shell is concentrated between a depth of $195-210 \mathrm{~cm}$, but there are also noticeable peaks between $140-145 \mathrm{~cm}$ and $225-230 \mathrm{~cm}$. If the dates for the adzes are sidelined, a depth of 140-145 cm indicates deposition at the Pleistocene/Holocene transition. Dates from 190-230 cm group around 25-35 kyr, with the exception of a couple of Early Holocene dates on Turbo shell. As mentioned above, other Turbo shell recorded here tended to have evidence of use and deposition by terrestrial hermit crabs, and their ability to confound radiocarbon sequences is well reported (Szabó 2012).

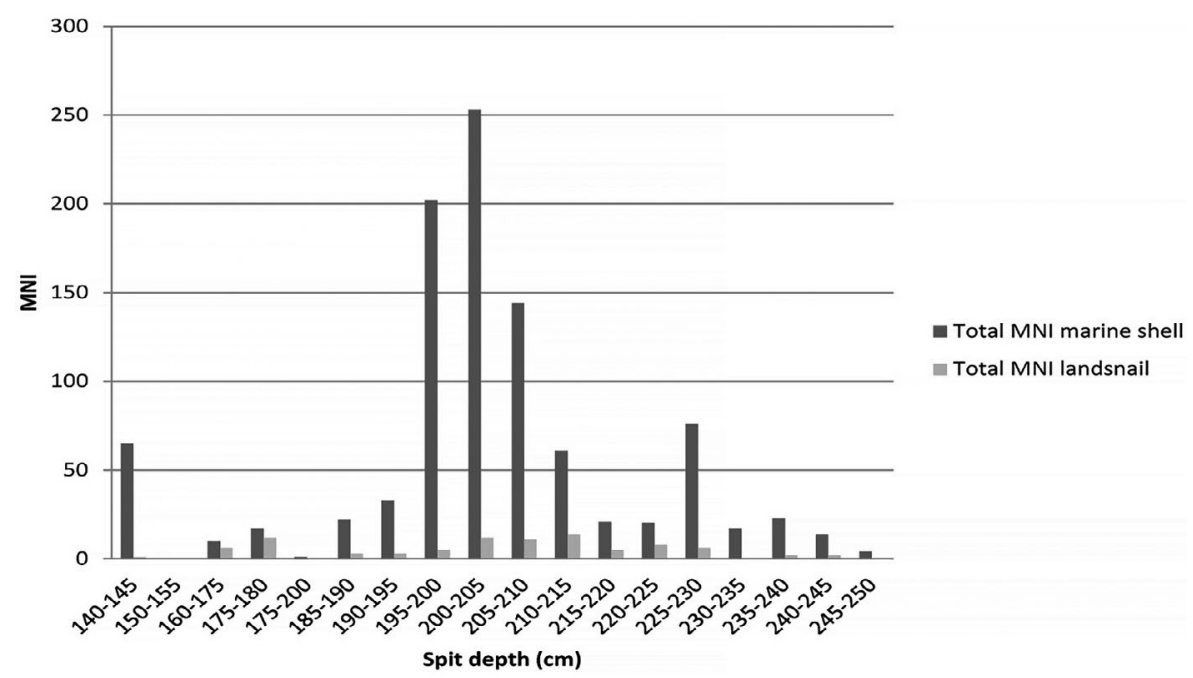

Figure 10.14 Graph to show total abundances (MNI) of marine and terrestrial molluscs per spit for Golo Square M4.

Source: Katherine Szabó and Annette Oertle. 


\begin{tabular}{|c|c|c|c|c|c|c|c|c|c|c|c|c|c|c|c|c|c|c|c|c|}
\hline & $\begin{array}{l}\frac{n}{0} \\
\stackrel{\underline{\pi}}{0} \\
\end{array}$ & - & $\approx$ & के & 馬 & - & -1 & - & -- & $a$ & & $m$ & \begin{tabular}{l|l}
$\operatorname{m}$ & 1
\end{tabular} & & & $\nabla \mid m$ & in & - & - & - \\
\hline & 岁怘 & & & $\sigma$ & & & & & & & & & & & & & & & & \\
\hline & 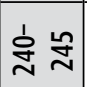 & & & $\infty$ & $m$ & & & & & & & & & & $\sim$ & & & & & \\
\hline & 岕导 & & & $\circ$ & $\nabla$ & & & & & & & & T & - & $\nabla$ & - & & & & \\
\hline & $\stackrel{\oplus}{\sim} \stackrel{\sim}{\sim}$ & & & 0 & $\sim$ & & & & & $\sim$ & & a & 7 & $r$ & $m$ & - & & & & \\
\hline & ڤ & & $r$ & 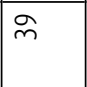 & 잉 & -1 & & & & & & & 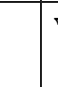 & $r$ & $\underline{6}$ & & & & & \\
\hline & $\stackrel{\sim}{\sim} \underset{\sim}{\approx}$ & & $\sim$ & 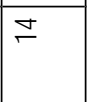 & $\sim$ & & & & & & & & & & $\sim$ & & & & & \\
\hline & $\stackrel{\stackrel{n}{\sim}}{\underset{N}{N}}$ & & - & $a$ & Ln & & & & & & & & & & $m$ & & & & & \\
\hline & 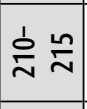 & & $a$ & $\stackrel{\infty}{\sim}$ & 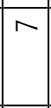 & a & & - & - & & & - & & & 0 & & & & & \\
\hline 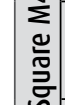 & 客 은 & & $m$ & $\tilde{b}$ & $\grave{\sim}$ & & & & $\bar{\tau}$ & - & & & a & & থ & & & - & & \\
\hline & 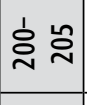 & $r$ & $\stackrel{\sim}{m}$ & ○ & $\stackrel{\infty}{\circ}$ & & & & & $\sim$ & & $\bar{T}$ & -1 & - & $m$ & - & & & & \\
\hline & 잉 유 & & $\stackrel{\infty}{\ulcorner}$ & 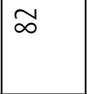 & $\tilde{6}$ & & & & & $\sim$ & -1 & $\sim$ & & & 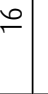 & & & & - & \\
\hline & $\stackrel{1}{\circ} \stackrel{2}{\circ}$ & & $\nabla$ & I & - & & & & & & & - & - & & & & - & & & \\
\hline & 官 ఏ & & $\sim$ & $a$ & $\nabla$ & & - & & & & & - & -1 & - & & & & & & \\
\hline & 송 号 & & & & & & & & & & & & ( & - & & & & & & \\
\hline & $\stackrel{1}{\stackrel{1}{⺊}} \stackrel{\infty}{\leftarrow}$ & & $\sim$ & r & $\infty$ & & & & & & & & & & & & & & & \\
\hline & 홍 & & & & & & & & & & & - & -1 & - & $\nabla$ & & & & & \\
\hline & 운 는 & & & & & & & & & & & & & & & & & & & \\
\hline & 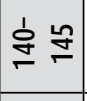 & & & $F$ & & & & & & $\sim$ & - & - & - & & $\vec{m}$. & $\nabla$ & $\nabla$ & & & - \\
\hline 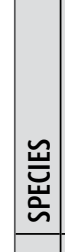 & & 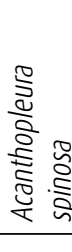 & 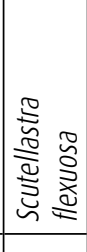 & 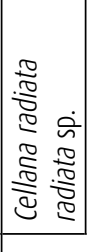 & 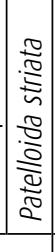 & 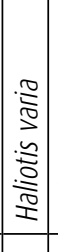 & 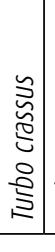 & 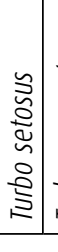 & 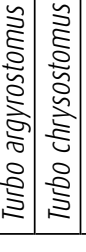 & 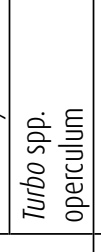 & 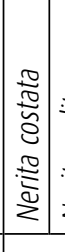 & 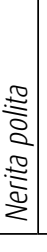 & 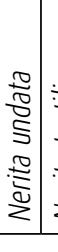 & 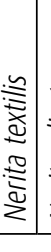 & 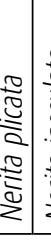 & 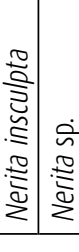 & 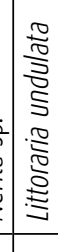 & 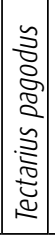 & 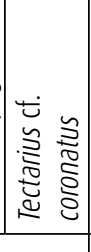 & 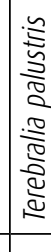 \\
\hline 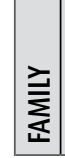 & & 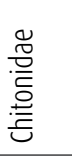 & 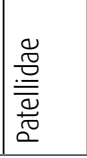 & 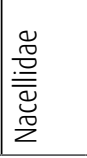 & & 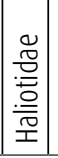 & 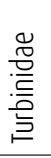 & & & & 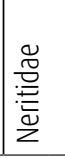 & & & & & & 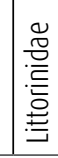 & & & . \\
\hline
\end{tabular}




\begin{tabular}{|c|c|c|c|c|c|c|c|c|c|c|c|c|c|c|c|c|c|c|c|c|c|}
\hline & $\frac{n}{0}$ & & & - & - & - & - & - & 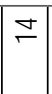 & $\simeq$ & - & - & $-r^{-} \sim$ & $-F$ & \begin{tabular}{ll|}
$n$ & $m$
\end{tabular} & \begin{tabular}{l|l|}
- & $\sim$ \\
\end{tabular} & \begin{tabular}{l|l}
$m$ & $\sim$
\end{tabular} & $\begin{array}{ll}N & -\end{array}$ & - & & $m$ \\
\hline & 守 옳 & & & & & & & & & & & & & & & & & & & & \\
\hline & 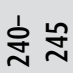 & & & & & & & & & & & & & & & & & & & & \\
\hline & & & & & & & & & & $\sim$ & & & & & & & & & & & - \\
\hline & 官 $\stackrel{\sim}{\sim}$ & & & & & & & & & & & & & & & & - & & & & \\
\hline & ฝે & & & & & & & & & & - & & & & & & & & & & \\
\hline & 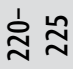 & & & & & & & & & & & & & & & & & & & & \\
\hline & $\stackrel{\omega}{\underset{\sim}{\sim}} \underset{\mathbb{N}}{\mathbb{N}}$ & & & & & & -1 & & - & & & & & 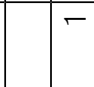 & - & & & & & & \\
\hline & 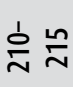 & & & & & - & & & $\sim$ & $\sim$ & & & & - & - & & $\sim$ & & & & \\
\hline $\begin{array}{l}\sum_{0}^{2} \\
\text { o } \\
\end{array}$ & 崇只 & & & & & & & & $\sim$ & 0 & & & - & $\sim$ & $\begin{array}{lll}N & -\end{array}$ & - & $m$ & & - & - & \\
\hline & ¿्丶 & & & - & & & & & $m$ & $\sim$ & & - & & 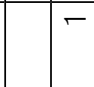 & - & & \begin{tabular}{|c|c|} 
& $\sim$ \\
\end{tabular} & & & & \\
\hline & 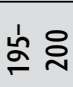 & & - & & - & & & & 0 & & & & & & - & - & & & & & - \\
\hline & よِ & - & & & & & & & & & & & & & & & & - & & & - \\
\hline & 岕 号 & & & & & & & & & & & & & & - & - & & & & & \\
\hline & 占 号 & & & & & & & & & & & & & & & & & & & & \\
\hline & $\stackrel{\text { L }}{\stackrel{2}{=}}$ & & & & & & & & & & & & & & & & & & & & \\
\hline & 응 솓 & & & & & & & - & & & & & - & - & & & & & & & \\
\hline & 은 음 & & & & & & & & & & & & & & & & & & & & \\
\hline & 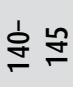 & & & & & & & & & & & & - & & & & & & & & \\
\hline 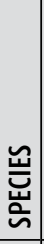 & & 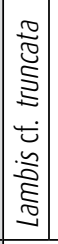 & 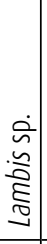 & 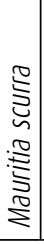 & 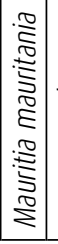 & 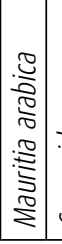 & 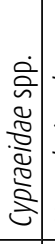 & 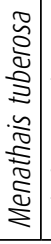 & 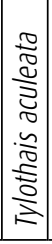 & 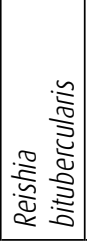 & 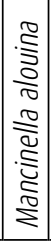 & 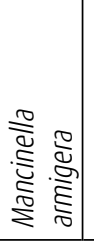 & 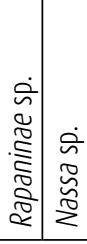 & 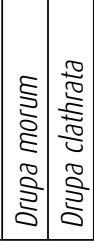 & 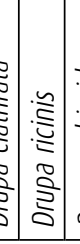 & 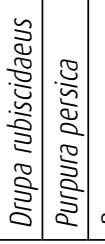 & 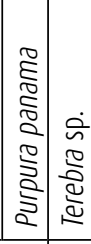 & 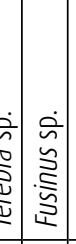 & 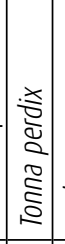 & $\begin{array}{l} \\
\dot{\hat{n}} \\
\frac{\varrho}{\otimes}\end{array}$ & 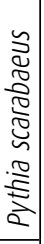 \\
\hline 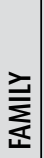 & & 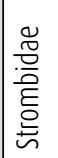 & & 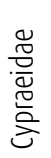 & & & & 兽 & & & & & & & & & 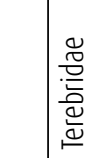 & 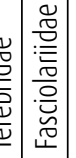 & 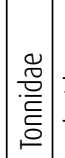 & $\begin{array}{l} \\
\mathbb{0} \\
\frac{0}{0} \\
\overline{5} \\
9\end{array}$ & 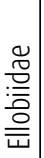 \\
\hline
\end{tabular}


The Spice Islands in Prehistory

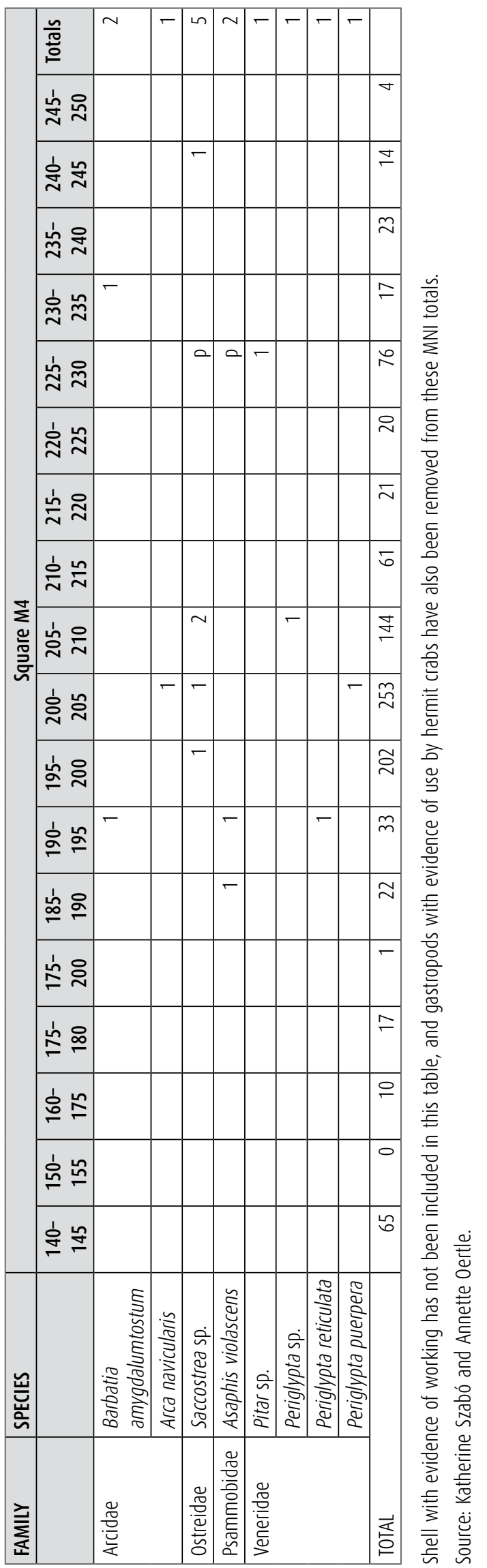

\begin{tabular}{|c|c|c|c|c|c|c|}
\hline & & $\stackrel{m}{m}$ & & & $\mid \widetilde{\sigma}$ & 2 \\
\hline & 宗怘 & & & & & \\
\hline & 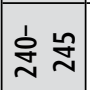 & & & & & \\
\hline & $\underset{\sim}{\sim} \underset{\sim}{\sim} \stackrel{P}{\sim}$ & & & & $\sim$ & - \\
\hline & $\dot{\tilde{N}} \tilde{\sim}$ & & & & & \\
\hline & 岕 & & - & & $m$ & \\
\hline & $\underset{\sim}{2} \approx$ & v & & - & $\ln \mid$ & $\infty$ \\
\hline & $\stackrel{\dot{\omega}}{\sim} \underset{N}{\sim}$ & & & - & $m$ & $\sim n$ \\
\hline & $\frac{\dot{\partial}}{\sim} \stackrel{n}{\sim}$ & & $\sim$ & & $a$ & 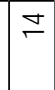 \\
\hline 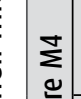 & 㟋咞 & & & & & $F$ \\
\hline 兽 & ذ્ّ & & $m \mid$ & & 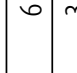 & $\simeq$ \\
\hline & 占 。 & & & & $|\ln |$ & \\
\hline & $\underset{\sigma}{2} \stackrel{2}{2}$ & & m & & 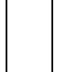 & $\mathrm{m}$ \\
\hline & 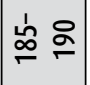 & & & & $m$ & $\mathrm{~m}$ \\
\hline & 힝 & & & & & 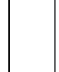 \\
\hline & 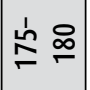 & & & & $\simeq$ & $\simeq$ \\
\hline & 흥 & & & & 0 & 0 \\
\hline & 总号 & & & & & \\
\hline & 守 导 & & & & & - \\
\hline 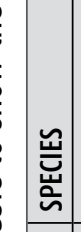 & & 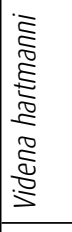 & 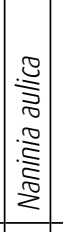 & 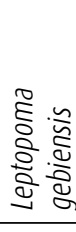 & 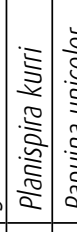 & \\
\hline 文 & & 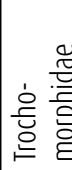 & 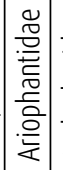 & $\begin{array}{l}\text { 总 } \\
\text { 产 } \\
\text { 言 } \\
\end{array}$ & 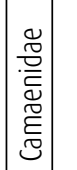 & $\mid \overrightarrow{\underline{s}}$ \\
\hline
\end{tabular}


In terms of their composition, the peaks are similar with all being comprised of combinations of the dominant four species (see Fig. 10.15). Nerita plicata and Cellana radiata are present throughout the represented sequence, but $N$. plicata is dominant in the uppermost peak $(140-45 \mathrm{~cm})$, while C. radiata dominates from $185 \mathrm{~cm}$ to the basal spit $(250 \mathrm{~cm})$. Both Patelloida striata and Scutellastra flexuosa occur from $175 \mathrm{~cm}$ downwards to near the base of the deposits. All four of these species are characteristic of intertidal hard-shores, and all are capable of living on exposed shores where they are subject to periodic wave action. The general lack of variation in both the dominant species, and - when all recovered marine shell midden species are consideredthe hard-shore intertidal niche suggests that this habitat was accessible to the Golo inhabitants throughout the Pleistocene occupation and remained relatively stable. Nearly all identified species could have been easily gathered from the substrate and within fissures and tide pools at low tide.

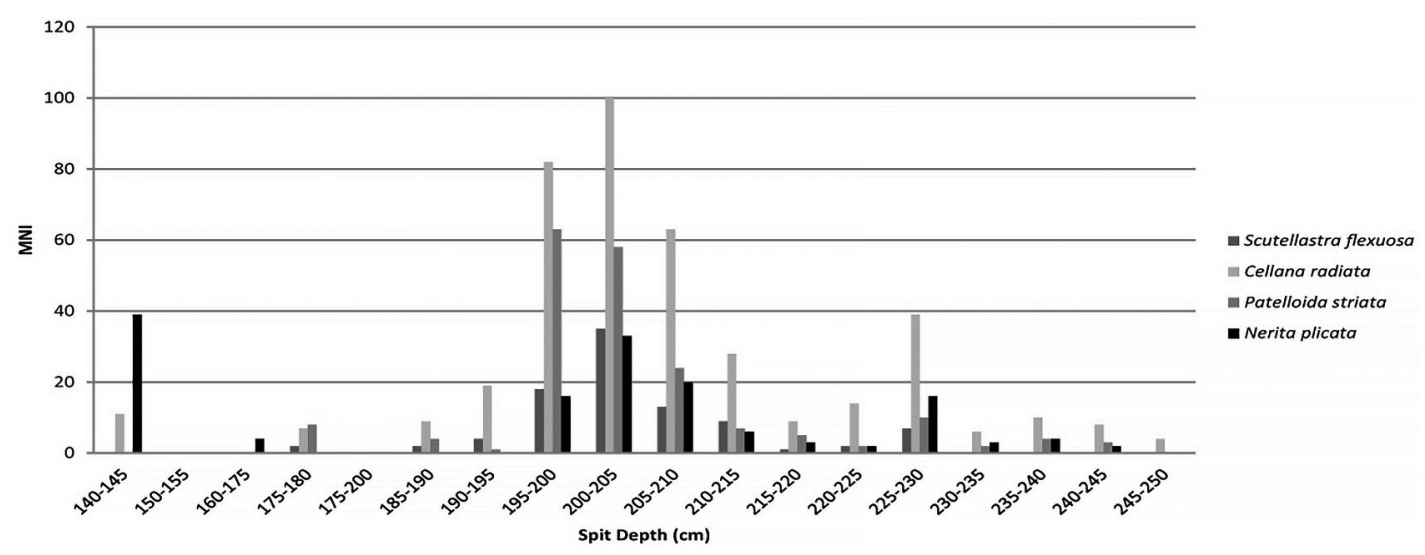

Figure 10.15 Relative abundances (MNI) of the four major molluscan species represented within the Golo Square M4 sample.

Source: Katherine Szabó and Annette Oertle.

Terrestrial snails are found in low levels in association with marine shells throughout the M4 sample. The literature on the non-marine mollusca of Gebe Island is sparse, but fortuitously a new review with additional data was published recently by Grieke (2012). This has allowed refinement of the original identifications made as part of Szabós 2002/03 analysis (see Table 10.13). The identified species tend to be of a moderate size, with Planispira kurri and Naninia aulica being of equivalent size, or larger than, the average nerite. Videna hartmanni, Leptopoma gebiensis, and Papuina unicolor are slightly smaller, but certainly not diminutive. The larger two species, and indeed all five, could viably represent a food source.

In the course of the analysis of the molluscan remains from the Niah Caves in Sarawak, Borneo, Szabó (2016) developed a series of criteria for establishing whether terrestrial snails in archaeological deposits were likely to represent a collected food source, or whether they were self-introduced into deposits. These criteria included observations about the representation of terrestrial snail species of different sizes, whether the distribution of the occurrence of land snails mapped on to, or outgrouped from, marine/freshwater shell midden stratigraphically, and whether terrestrial snail remains were predominantly found near the cave mouth. While the terrestrial snails found in the West Mouth of the Niah Caves were determined to be clearly self-introduced, the Golo Cave M4 sample is not so clear-cut. The frequencies of terrestrial snails track, rather than mirror, the abundances of marine shell (Fig. 10.14, Table 10.12). There is also a tendency towards larger species and specimens, although whether this may be an artefact of sampling is difficult to say. The small overall nature of the sample, as well as the ambiguities around chronostratigraphy, makes a definitive case for deliberate collection impossible. However, what can be said is that the M4 terrestrial snail assemblage shows none of the hallmarks characteristic of a self-introduced assemblage. 


\section{Discussion (Golo shell midden)}

Although the available sample of shell midden does not capture the Holocene/Terminal Pleistocene portions of the Golo chronostratigraphic sequence, and thus cannot be directly compared with the vertebrate faunal assemblage, it does offer unique insights into Late Pleistocene subsistence at Golo where a bone record is silent. Limpets and neritids dominate, supplemented by lower numbers of other species that, for the most part, also inhabit the intertidal hard-shore. These species are able to withstand dynamic wave action, and the conditions of the coastal zone in the past seem to largely mirror those that exist today. Dwelling on rocky surfaces, and within fissures and tide pools, the species that constitute the M4 Pleistocene assemblage would have been simple to gather and provided a food source that was consistently available with the low tide.

The reliance on the hard-shore intertidal zone for the gathering of shellfish for consumption contrasts sharply with the zones necessarily exploited for the collection of molluscan raw materials for artefact production. With regards to species selected for working in the Pleistocene, Turbo marmoratus inhabit lagoonal habitats and, as argued in Szabó et al. (2007), the presence of the opercula as well as the lack of any evidence for bioerosion of the shells' interior or attrition caused by beach-rolling, suggests live collection. Very low occurrences of other taxa from lagoonal, subtidal habitats further demonstrate the exploitation of this zone by Pleistocene Golo occupants. Such subtidal species include the large spider conch Lambis truncata, the Partridge ton Tonna perdix and the baler shell Melo sp. It is possible that all of these species were collected with artefact production in mind, with Lambis spp. and Melo sp. being occasional raw materials across the region and exotic Tonna dolium identified within the freshwater midden at the Gan Kira entrance of the Niah Caves in Borneo (Szabó et al. 2013). The presence of fragments of Nautilus sp. body and septal chamber walls also indicates the collection of molluscan resources not necessarily tied to subsistence, and experimental work by Parkinson (2016) has shown clear evidence of working on some fragments. Of the array of shell species selected for artefact production, the only species that overlaps with the midden shell in type and habitat is Scutellastra flexuosa, which has been shown to have been occasionally repurposed from the midden as a cutting/scraping tool (Szabó and Koppel 2015).

The presence of a Pleistocene sequence where bone is entirely absent, yet molluscan shell is present and well-preserved seems highly anomalous and in want of explanation, yet this patterning is not without regional precedent. The two most notable analogies are the sequences from Leang Sarru on Salibabu Island, and earlier excavations at Leang Tuwo Mane'e on Karakelang Island, both in the Talaud group, which lies between the large Philippine island of Mindanao and Indonesian island of Sulawesi (Bellwood 1976; Ono et al. 2010; Tanudirjo 2005). The Leang Tuwo Mane'e deposits take in preceramic and ceramic material from c. 6000-1000 BP and fish bone is only reported from very recent deposits within the site, despite the presence of quantities of marine shell throughout (Bellwood 1976). The Leang Sarru sequence takes in a greater length of time, spanning from $-34,000$ years through to upper earthenware-bearing deposits (Tanudirjo 2005; Ono et al. 2010). Shell midden and stone artefacts were recovered from throughout the sequence, with earthenware potsherds restricted to the upper deposits. No bone at all was recovered.

As with Golo Cave, Leang Tuwo Mane'e and Leang Sarru are limestone rockshelters, and so there would seem to be no prima facie reason why there should not be preservation of bone. Bellwood (1976:243) and Ono et al. $(2010: 323,334)$ both point to the impoverished nature of the Talaud fauna with a lack of native mammals/marsupials and the dominant local terrestrial vertebrate fauna being rodents and bats/flying foxes. Presumably small reptiles, amphibians, and birds are also locally available, and fish would likewise have been accessible. Ono et al. (2010:323) suggests the fragility of fishbone could be a factor in their absence, but again the well-preserved nature of the shell requires a stronger taphonomic case to be made for the absence of bone. 
Based on the current evidence from Golo Cave, coupled with Leang Tuwo Mane'e and Leang Sarru, there appears to be an economic pattern of reliance on marine invertebrate fauna during Pleistocene occupation on small, impoverished, and relatively remote Wallacean Islands. The very high totals of starch grains identified from the lowest layers of Golo Cave (see Chapter 2) may also be telling us something of the structure of Pleistocene subsistence. Rather than assuming the absence of bone is a taphonomic issue, it would be interesting to place greater focus upon understanding how such an apparently limited subsistence base supported continued occupation through the collection and study of fuller sequences. Is evidence of fishing to be found on the less exposed shores of Gebe, thus more closely aligning with records from Timor and surrounding islands (e.g. O'Connor et al. 2011; Samper Carro et al. 2016)? The repercussions of this reliance on marine invertebrate, and particularly molluscan, resources for the development and diversification of Pleistocene shell-working in the region would also benefit from a more detailed understanding of the available resources and economic behaviours of Pleistocene residents of islands such as Gebe. 
This text is taken from The Spice Islands in Prehistory: Archaeology in the Northern Moluccas, Indonesia, edited by Peter Bellwood, published 2019 by ANU Press, The Australian National University, Canberra, Australia.

doi.org/10.22459/TA50.2019.10 